\title{
Effect of Heat Treatment on Mechanical and Thermal Properties of SiC/SiC Composites With Three-Dimensional Carbon Network
}

Jie Chen

Northwestern Polytechnical University

Yongsheng Liu ( $\square$ yongshengliu@nwpu.edu.cn )

Northwestern Polytechnical University https://orcid.org/0000-0002-9020-7202

Yunhai Zhang

Northwestern Polytechnical University

Jing Wang

Northwestern Polytechnical University

Liyang Cao

Northwestern Polytechnical University

Yu Pan

National University of Defense Technology

\section{Research Article}

Keywords: carbon network, thermal conductivity, nanoindentation, bending strength

Posted Date: February 17th, 2021

DOI: https://doi.org/10.21203/rs.3.rs-200488/v1

License: () (1) This work is licensed under a Creative Commons Attribution 4.0 International License.

Read Full License 


\title{
Effect of heat treatment on mechanical and thermal properties of $\mathrm{SiC} / \mathrm{SiC}$ composites with three-dimensional carbon network
}

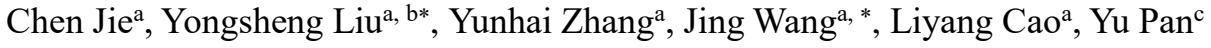 \\ ${ }^{a}$ Science and Technology on Thermostructural Composite Materials Laboratory, Northwestern \\ Polytechnical University, Xi'an, Shaanxi 710072, China \\ ${ }^{b} N P U-S A S$ Joint Research Center of Advanced Ceramics, Northwestern Polytechnical University, \\ Xi'an, Shaanxi 710072, China \\ ${ }^{c}$ Department of Aerospace and Material, National University of Defense Technology, Changsha, \\ Hunan 410073, China
}

\begin{abstract}
$\mathrm{SiC} / \mathrm{SiC}$ composites with high thermal conductivity shows promising application in field of fusion reactors. In this work, CNTs papers were fabricated by a vacuum filtration strategy while using pitch-based carbon fibers to build a network structure into $\mathrm{SiC} / \mathrm{SiC}$ composite ( $\mathrm{SiC}-\mathrm{CNTs}-\mathrm{C} / \mathrm{SiC}, \mathrm{SCCS}$ ). The thermal conductivity and related mechanical properties before and after heat treatment at different temperature were investigated. The bonding between CNTs paper layers and SiC matrix were mainly mechanical. Compared to the composite without transfer channels, the bending strength of SCCS (434.54MPa) increased by $19 \%$ due to the reinforcement of transfer channels from the network structure. However, the damage to $\mathrm{SiC}$ fibers resulting from high temperature treatment adversely affected the mechanical properties. The disorder degree of SiC matrix and SiC fibers decreased after heat treatment while mean free path of phonons increased, which are conducive to heat transfer. Contracted to room temperature, the measured thermal conductivity at $1600^{\circ} \mathrm{C}$ was $53.83 \mathrm{~W} /(\mathrm{m} \cdot \mathrm{K})$ in vertical direction and $29.85 \mathrm{~W} /(\mathrm{m} \cdot \mathrm{K})$ in plane. In summary, heat treatment apparently enhanced thermal conductivity of SCCS composites while partly sacrificed the mechanical properties.
\end{abstract}

\footnotetext{
* Corresponding author. Tel.: +86 029 88495179; Fax: +86 02988494620

E-mail: yongshengliu@nwpu.edu.cn

* Corresponding author. Tel.: +86 029 88495179; Fax: +86 02988494620

E-mail: wangjing1@nwpu.edu.cn
} 
Key words: carbon network, thermal conductivity, nanoindentation, bending strength

\section{Introduction}

Continuous $\mathrm{SiC}$ fiber reinforced $\mathrm{SiC}$ ceramic matrix composites $(\mathrm{SiC} / \mathrm{SiC})$ are excellent in high temperature strength ${ }^{[1]}$, oxidation resistance ${ }^{[2,3]}$ and irradiation performance $^{[4,5]}$. In nuclear application, it is important that the heat dissipation performance of fuel cladding tube, which means high thermal conductivity is essential for materials during service. $\mathrm{SiC} / \mathrm{SiC}$ composites have been considered as potential structure materials for cladding tube ${ }^{[6,7]}$. It is always expected to improve thermal conductivity of $\mathrm{SiC} / \mathrm{SiC}$ composites.

There is a wide variation in the thermal conductivity data of $\mathrm{SiC} / \mathrm{SiC}$ composites depending on various preforms, composition and preparation process. Katoh et al. ${ }^{[8]}$ found three-dimensional (3D) $\mathrm{SiC} / \mathrm{SiC}$ composites had the best thermal conductivity after comparing the data of $\mathrm{SiC} / \mathrm{SiC}$ composites with $2 \mathrm{D} \mathrm{SiC} / \mathrm{SiC}$ composites. Yamada et al. ${ }^{[9]}$ proved that the thermal conductivity of $3 \mathrm{D} \mathrm{SiC/SiC}$ composites could reach 40 $50 \mathrm{~W} /(\mathrm{m} \cdot \mathrm{K})$ at room temperature $(\mathrm{RT})$. Yet it is hard to weave three-dimensional preforms for the high modulus of $\mathrm{SiC}$ fibers ${ }^{[10]}$. In addition, the cost of fabricating 3D $\mathrm{SiC} / \mathrm{SiC}$ is expensive. Densifying $\mathrm{SiC} / \mathrm{SiC}$ composites is also a favorable strategy to improve its thermal conductivity. For instance, Tao et al. ${ }^{[11]}$ reduced the porosity of composites via depositing $\mathrm{SiC}$ nanowires on $\mathrm{SiC}$ fabrics and the thermal conductivity reached $26.7 \mathrm{~W} /(\mathrm{m} \cdot \mathrm{K})$ at room temperature. In addition, many research efforts were devoted to introduce second phase into composites for improving thermal conductivity. Carbon nanotubes (CNTs) have a large mean free path of phonons because of their high aspect ratio, and the theoretical thermal conductivity can reach $3000 \mathrm{~W} /(\mathrm{m} \mathrm{K}) \cdot{ }^{[12]}$ Feng et al. ${ }^{[13]}$ added CNTs films to the preform, which increased thermal conductivity to 23.9 $\mathrm{W} /(\mathrm{m} \cdot \mathrm{K})$. Feng et $\mathrm{al}^{[14]}$ introduced CNTs into PyC interface and the thermal conductivity increased by 2.158 times due to the decline of interface thermal resistance. In the research of Yoshida et al. ${ }^{[15]}$, submicron-sized $\alpha$-SiC with coarse $\alpha$-SiC particles addition was used as raw materials for $\mathrm{SiC}$ matrix, which improved the thermal conductivity to $56 \mathrm{~W} /(\mathrm{m} \cdot \mathrm{K})$. However, the mechanical properties of $\mathrm{SiC} / \mathrm{SiC}$ composites in literatures could not meet the requirements, which were equally important for nuclear application.

As for effect of preparation process, several techniques have been reported to fabricate $\mathrm{SiC} / \mathrm{SiC}$ composites, such as Chemical Vapor Infiltration $(\mathrm{CVI})^{[16]}$, Polymer 
Impregnation and Pyrolysis (PIP) ${ }^{[17]}$, Nano-Infiltration and Transient Eutectic-phase $(\mathrm{NITE})^{[18]}$, Reaction Sintering (RS) ${ }^{[19]}$ and Electrophoretic Deposition (EPD) ${ }^{[20]}$. All these strategies have non-ignorable disadvantages for thermal applications. Comparing with other processes, the bottle-neck effect of CVI process generates high porosity. The existence of pores results in the low thermal conductivity of $\mathrm{SiC} / \mathrm{SiC}$ at room temperature ${ }^{[19]}$. However, the temperature of CVI process is low which has little damage to $\mathrm{SiC}$ fibers. Besides, CVI method yields stoichiometric and crystalline $\beta$-SiC matrix with fine-grained microstructure, which are preferred for heat conduction. In our previous work, laser-assisted CVI (LA-CVI) method combining CVI with laser processing was used to establish a CVI mass transfer channel ${ }^{[21-25]}$. The mass transfer channel not only increased the density, but also strengthened the mechanical properties and thermal conductivity of $\mathrm{C} / \mathrm{SiC}$ composites. Furthermore, heat treatment has been employed to release thermal residual stress, enhance thermal stability, improve interface crystallinity. Ma et al. ${ }^{[26]}$ noticed the enhancement in flexural strength and fracture toughness of $\mathrm{SiC} / \mathrm{BN} / \mathrm{SiC}$ composites after heat treatment at $1300^{\circ} \mathrm{C}$. Feng et al. ${ }^{[27]}$ increased thermal conductivity of $\mathrm{SiC} / \mathrm{SiC}$ to $138.4 \mathrm{~W} /(\mathrm{m} \cdot \mathrm{K})$ at room temperature through $1900^{\circ} \mathrm{C}$ heat treatment. Although excellent thermal conductivity were shown in this work. Nevertheless, the loading capacity of $\mathrm{SiC}$ fibers would be seriously damaged due to the growth of $\mathrm{SiC}$ grains and the decomposition of amorphous $\mathrm{SiOC}^{[28]}$.

In this study, laser technology with high machining accuracy and fast processing speed $^{[29]}$ was applied to manufacture mass transfer channels. Then transfer channels were filled by pitched-based C fibers and constructed a network structure with CNTs papers in $\mathrm{SiC} / \mathrm{SiC}$ composites, which made the integration of structure and function. Subsequently, heat treatment process was employed to improve the thermal conductivity of SiC-CNTs-C/SiC composite.

\section{Experimental}

\subsection{Materials}

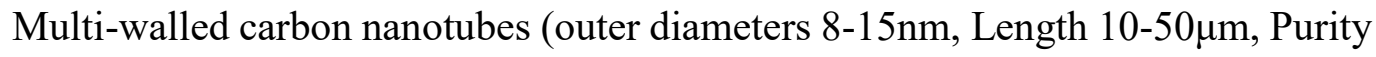
$>95$ wt\%) were supplied by Chengdu Organic Chemicals Co, Ltd., Chinese Academy of Sciences. SiC fabrics (0.5K, plain weave) were provided by Xiamen University. Pitch-based carbon fiber made in Shaanxi Tiance New Material Technology Co., Ltd., specific properties are shown in Table 1.

Table 1 Specific properties of pitch-based carbon fiber. 


\begin{tabular}{ccccc}
\hline C fiber & Strength/MPa & Modulus/GPa & $\begin{array}{c}\text { Linear } \\
\text { density/g/m }\end{array}$ & $\begin{array}{c}\text { Thermal } \\
\text { Conductivity/W/(m·K) }\end{array}$ \\
\hline 2082 & 843 & 0.4508 & 500 \\
\hline
\end{tabular}

\subsection{Preparation}

The procedure of making CNTs papers were described elsewhere ${ }^{[30]}$. Each paper contains $0.15 \mathrm{~g}$ CNTs. Use 4 layers of as-obtained CNTs papers and 10 layers of SiC clothes to prepare preforms. The stacking pattern is shown in Fig. 1. Pyrolytic carbon (PyC) interface with a thickness around 200nm was deposited on the preforms at $870^{\circ} \mathrm{Cin}$ a reduced pressure of $5 \mathrm{kPa}$. Then the $\mathrm{SiC}$ matrix was produced by CVI method, the details can be referred to Ref. ${ }^{[13]}$. SiC-CNTs/SiC composites were marked as SCS. Subsequently, femtosecond laser system was employed to process holes with a diameter of $0.5 \mathrm{~mm}$ on semi-dense SCS composite (density $2.2 \mathrm{~g} / \mathrm{cm}^{3}$ ). Parameters can be found in literature ${ }^{[21]}$. After that, pitch-based carbon fibers were introduced into holes, followed by CVI SiC matrix until completely dense. SiC-CNTs-C/SiC composites were named SCCS. Finally, the SCCS composites are vacuum heat treated at $1400^{\circ} \mathrm{C}$, $1500^{\circ} \mathrm{C}, 1600^{\circ} \mathrm{C}$ for $2 \mathrm{~h}$. The samples are labeled HT1400, HT1500, HT1600.

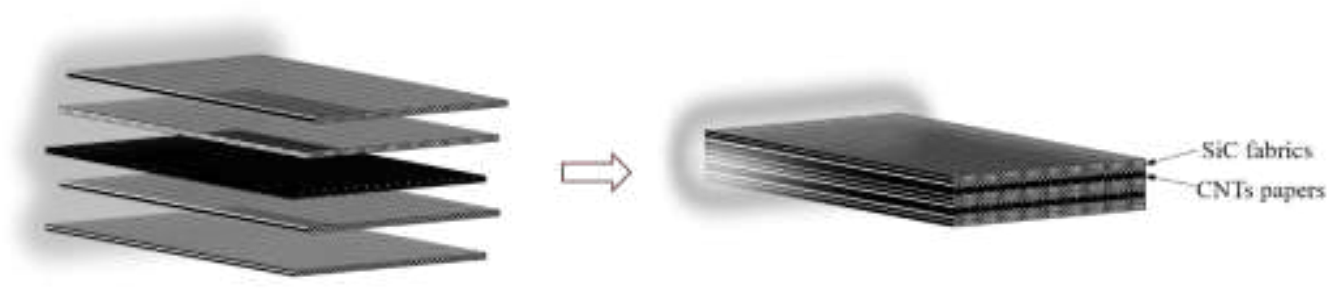

Fig. 1 Stacking pattern of SiC-CNTs/SiC composites(SCS).

\subsection{Characterization}

Archimedes method was used to measure the density of composites. The micromorphology was observed by scanning electron microscope (SEM, FEI, Helios G4 CX, USA). X-ray diffractometry (Rigaku D/max-2400, Japan) was employed to analyze the phase composition. The Elastic modulus and hardness of the CNTs papers and SiC fibers can be obtained by Nanoindentation technology. (Hysitron TI980, USA), which requires smooth surface of samples. The Young's modulus of the material can be calculated by Eq.(1).

$$
\frac{1}{E_{r}}=\frac{1-v_{\text {sample }}^{2}}{E_{\text {sample }}}+\frac{1-v_{\text {indenter }}^{2}}{E_{\text {indenter }}}
$$

Where $E_{r}$ is the modulus obtained from indentation test, $v$ represents the 
Poisson's ratio of the material, $E_{\text {sample }}$ and $E_{\text {indenter }}$ is the Young's modulus of the sample and the diamond indenter.

The interlaminar shear strength and three-point bending strength were obtained on a universal testing machine (CMT4304, China) at a room temperature and the loading rate was $0.5 \mathrm{~mm} / \mathrm{min}$. The size of three-point bending strength samples and interlaminar shear strength samples were $40 \mathrm{~mm} \times 5 \mathrm{~mm} \times 3 \mathrm{~mm}$ and $30 \mathrm{~mm} \times 15 \mathrm{~mm} \times 3 \mathrm{~mm}$ respectively. Thermal diffusivity is tested by laser flash method (LFA 427, NETZSCH, Germany) at room temperature with heating rate of $2{ }^{\circ} \mathrm{C} / \mathrm{min}$. The dimension of specimens were $\Phi 12.7 \mathrm{~mm} \times 3 \mathrm{~mm}$. Thermal conductivity was calculated by the formula:

$$
\lambda=\alpha \times C_{p} \times \rho
$$

where $\rho$ is the specimen density and $C p$ is the specific heat capacity.

\section{Results and discussion}

\subsection{Microstructure.}

The density of SiC/SiC, SCS, SCCS are $2.53,2.47$, and $2.49 \mathrm{~g} / \mathrm{cm}^{3}$ respectively. The detailed data of phases content has been shown in Table 2 .

Due to the introduction of CNTs papers, the volume fraction of SiC fiber decreased which leads to a decline in density of SCS. The morphologies of CNTs paper are exhibited in Fig. 2. Macroscopically, the carbon nanotube paper could be bent arbitrarily (Fig. 2(b)), and it had good flexibility. The surface of paper was uniform (as shown in Fig. 2(c)). At high magnification, CNTs were randomly distributed to form a network structure with many holes in CNTs paper, which was beneficial to the infiltration of $\mathrm{SiC}$ matrix.

Table 2 The volume fractions of SiC fiber, pitched-based carbon fiber and CNTs in SS, SCS, SCCS.

\begin{tabular}{cccccc}
\hline & $\begin{array}{c}\text { Volume } \\
\text { fractions of } \\
\text { SiC fiber }\end{array}$ & $\begin{array}{c}\text { Volume } \\
\text { fractions of } \\
\text { CNTs }\end{array}$ & $\begin{array}{c}\text { Volume } \\
\text { fractions of } \\
\text { Pitch-based C } \\
\text { fiber }\end{array}$ & Open Porosity & $\begin{array}{c}\text { Total } \\
\text { Porosity }\end{array}$ \\
\hline $\mathrm{SiC} / \mathrm{SiC}$ & $40 \%$ & - & - & $9 \%$ & \\
$\mathrm{SCS}$ & $30 \%$ & $6 \%$ & - & $7.2 \%$ & $22.1 \%$ \\
$\mathrm{SCCS}$ & $29.1 \%$ & $5.82 \%$ & $3 \%$ & $6.6 \%$ & $19 \%$ \\
\hline
\end{tabular}



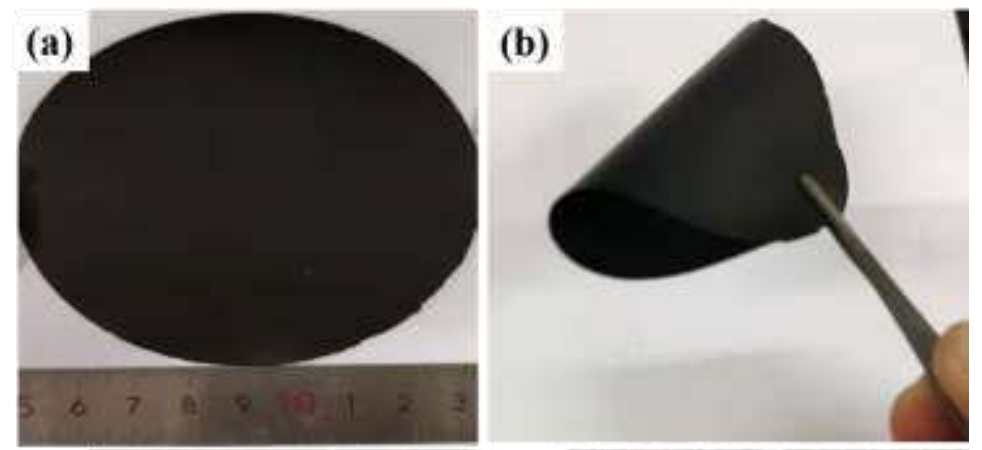

(c)

(d)
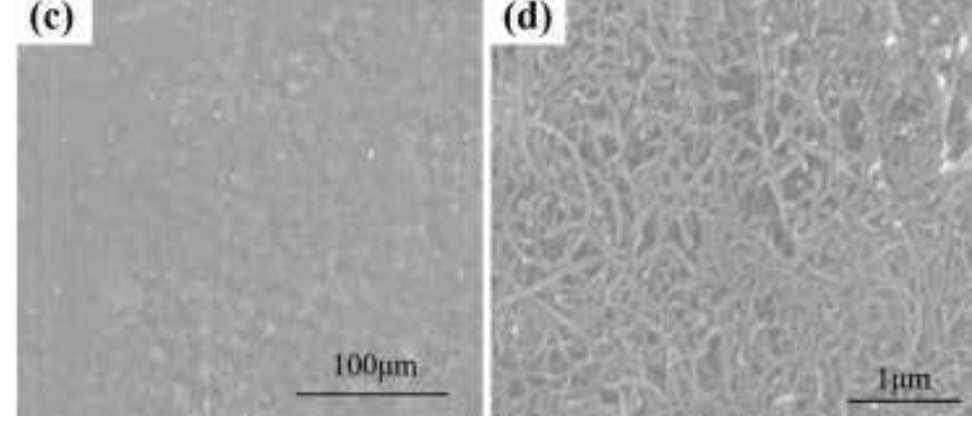

Fig. 2 Morphologies of CNTs paper. (a) macro view; (b) flexibility of CNT paper (c) CNT paper at low magnification; (d) CNT paper at high magnification.

As for the SCCS composites, its density was higher than that of the SCS composites. That means the existence of mass transfer channels was conducive to further densification of samples. The mass transfer channel opened the closed pores inside composites. During the subsequent CVI process, the reaction gas could infiltrate through the mass transfer channel, which effectively filled the internal pores of the composites and improved the density.

The cross-sectional morphologies of SCCS composites could be seen from Fig. 3. No gaps were observed between CNTs paper layers, SiC matrix and pitch-based carbon fibers. Heat treatment did not yields significant layer debonding in SCCS composite. A little matrix infiltrate into the CNTs papers during CVI process. CNTs paper layers were compact without pores. Atom diffusion was not found at interface from energy spectrum, which indicated that the bonded of interface between CNTs paper layer and $\mathrm{SiC}$ matrix was mechanically. This combination was achieved by the mutual restriction of the convex structure of the rough surface and friction. Yet the combination could not carried load effectively, when composite was subjected to a vertical force. 

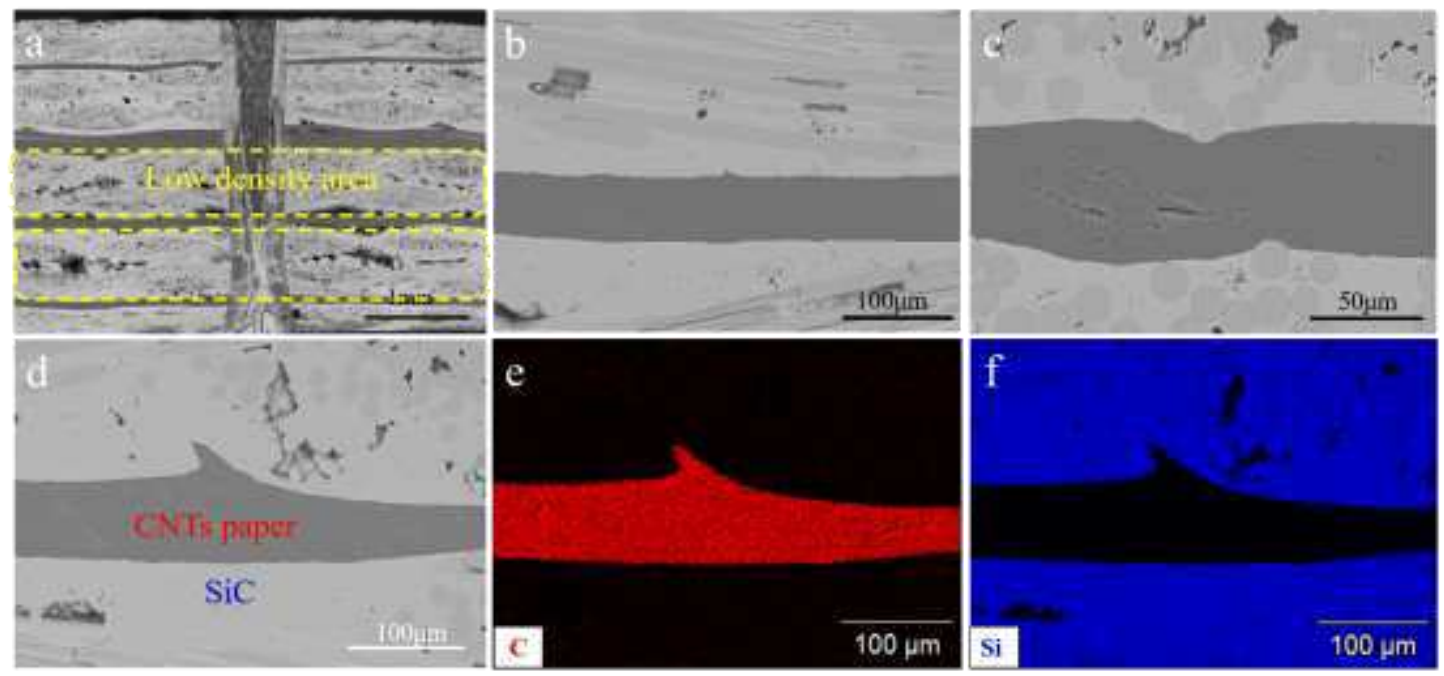

Fig. 3 Morphologies of CNTs paper layers in SCS composite. (a)-(c) BSE images of SCCS composite. (d)-(f) Energy dispersive near the CNTs papers.

After SCCS composites were heat-treated at $1400^{\circ} \mathrm{C}$ and $1500^{\circ} \mathrm{C}$ for 2 hours, the spherical morphology of SiC matrix between CNTs layers gradually became larger. The diameter of spherical SiC matrix further increased. As a result of matrix being treated at $1600^{\circ} \mathrm{C}$ for 2 hours, the surface morphology of $\mathrm{SiC}$ matrix showed two shapes: triangular pyramid-shaped sharp corners or hexagonal prism-shaped side protruding (circled part in the Fig.4), indicating that the SiC matrix grain growth had preferred orientation $^{[31]}$.

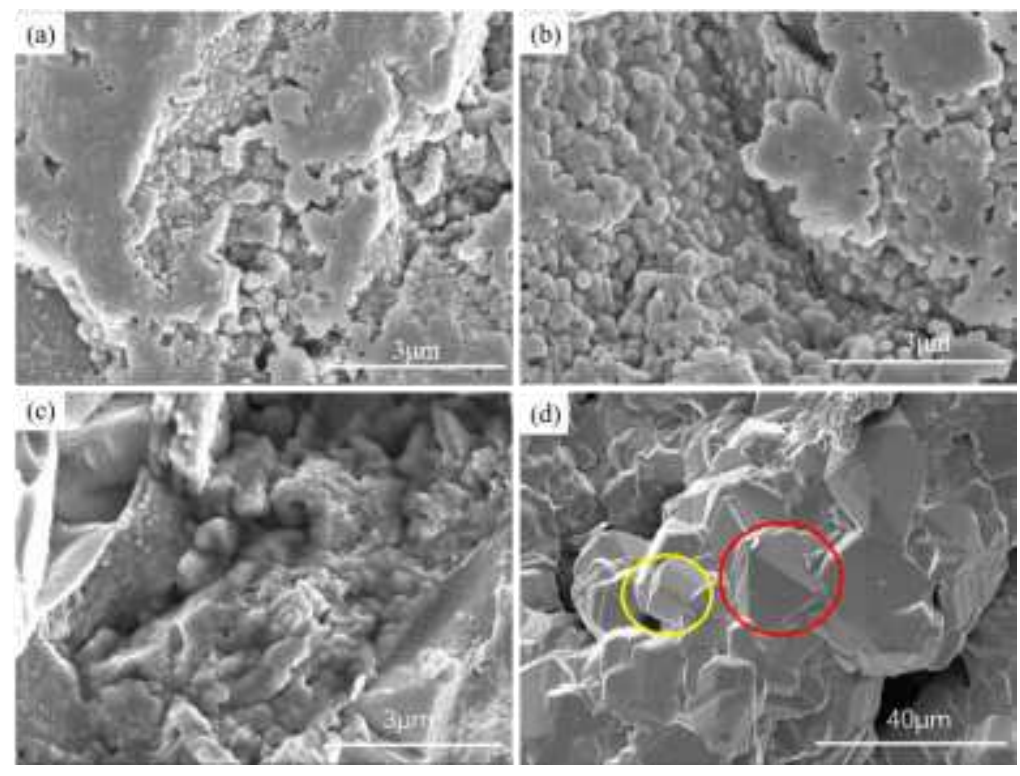

Fig. 4 Morphology of $\mathrm{SiC}$ matrix after heat treatment at different temperatures for 2 hours.

(a) Room temperature; (b) $1400^{\circ} \mathrm{C}$ treatment; (c) $1500^{\circ} \mathrm{C}$ treatment; (d) $1600^{\circ} \mathrm{C}$ treatment.

XRD patterns of samples after being treated at different temperatures were shown in Fig. 5. The SiC prepared by CVI was mainly composed of $\beta$-SiC nanocrystals, a 
small amount of $\alpha-\mathrm{SiC}$, amorphous $\mathrm{SiC}$ and a small amount of free carbon ${ }^{[32]}$. Due to the transformation of amorphous $\mathrm{SiC}$ matrix to $\beta$-SiC matrix, the crystallinity of SCCS composites increases, which caused the diffraction peaks of (111), (220) and (311) crystal planes of SiC matrix to gradually sharpen with the increase of temperature. The relative intensity of the (111) crystal plane increased, indicating that more $\mathrm{SiC}$ matrix tends to grew at the (111) crystal plane.

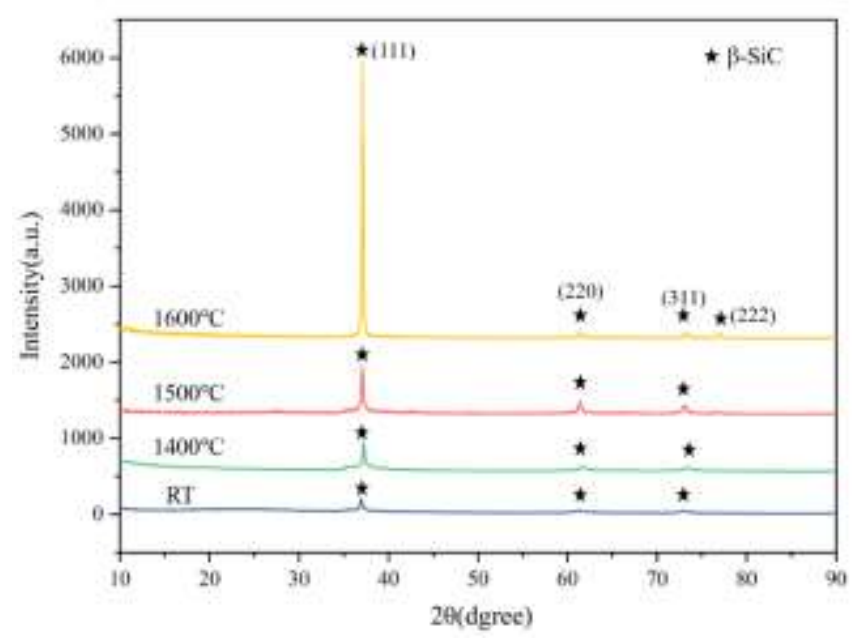

Fig. 5 X-ray diffraction patterns of samples at different heat treatment temperatures.

\subsection{Micromechanics}

Oliver and Pharr ${ }^{[33]}$ believed that the elastic modulus measured by nanoindentation method be an average value of the elastic modulus in different crystal axis directions. The nanoindentation Load-Displacement curves of CNTs paper layers after heat treatment at different temperatures were indicated for Fig. 6a. The ordinate represents the load, and the abscissa represents the depth of indenter. The slopes of the loading and unloading curves in Fig. 6a are not the same. The sample produces plastic deformation during the loading process. After unloading, the compressed area cannot be elastically deformed to return to its original state. In addition, the origin of loading curve was close to the end of unloading curve, which means the deformation was mainly elastic deformation and the plastic deformation was low. The maximum load for CNTs paper was $5 \mathrm{mN}$. However, the depth of indenters were different, indicating that hardness of four samples changed after heat treatment. 

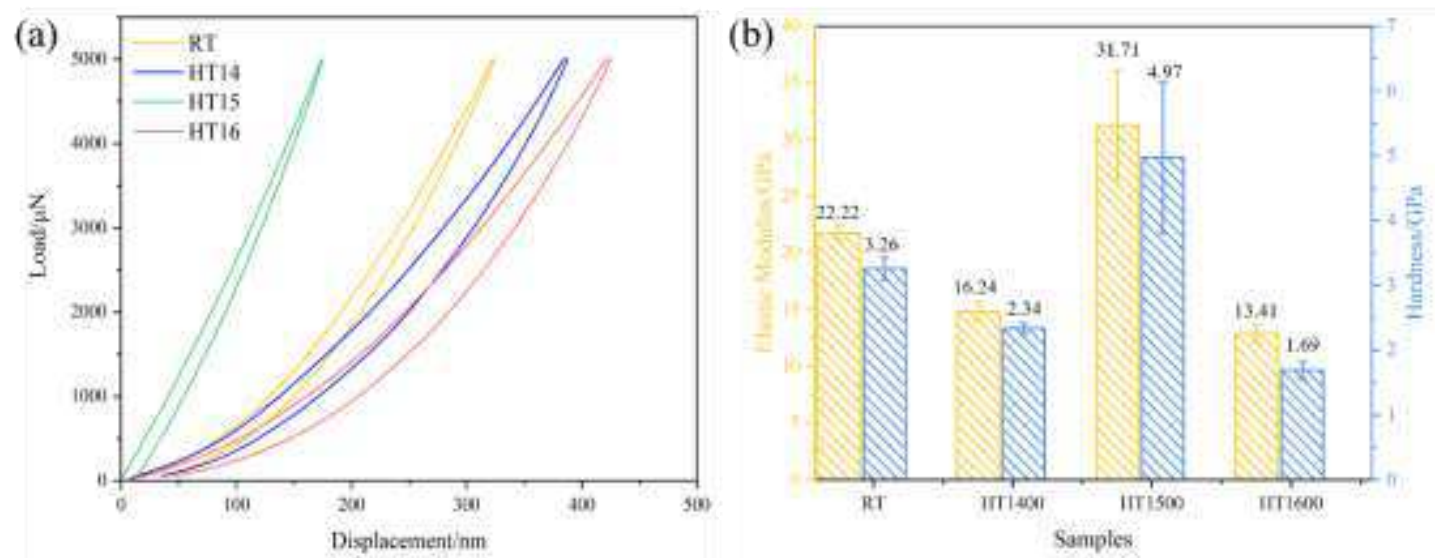

Fig. 6 Micromechanical properties of CNTs paper layers in SCCS composites (tested by nanoindentation).

(a) Load-Displacement curves of CNTs papers; (b) Elastic modulus and Hardness of CNTs papers after heat treatment.

Fig. $6 \mathrm{~b}$ lists the measured elastic modulus and hardness of CNTs paper layers according to Eq.(1). Generally, the elastic modulus of material is positively related to their hardness. The main factors affecting the elastic modulus of CNTs paper layers were combination, grain size and atomic arrangement. In CNTs paper layers, the bonding force between CNTs was mainly van der Waals force. While the bonding between $\mathrm{SiC}$ matrix and CNTs was mainly mechanical bonding. Therefore, the modulus and hardness of CNTs paper layers were much lower than that of SiC fibers. When the temperature of treatment raised, the grain size of $\mathrm{SiC}$ and CNTs increased ${ }^{[27]}$, which was smaller than dimension of indenter $(100 \mathrm{~nm})$. The relationship between hardness and grain size can be expressed as follows ${ }^{[34]}$ :

$$
H=H_{0}+K d^{-\frac{1}{2}}
$$

In formula, $H_{0}$ and $K$ are constants, $H$ represents the hardness, $d$ is the size of grain. With the size enlarged, the decrease of the number of grain boundaries that hinder slip reduced the hardness of CNTs paper layer. After $1600^{\circ} \mathrm{C}$ treatment, the hardness and modulus of CNTs paper layer decreased by $39.6 \%$ and $48.2 \%$ respectively.

\subsection{Mechanical properties}

In Fig. 3(a), the pitch-based-C fiber in transfer channel and CNTs papers form a macroscopic network structure, which has an important effect on the mechanical properties of SCCS composites. Bending strength of SCCS composites is listed in Fig. 8. The maximum flexural strength of SCCS composites reaches $434.54 \mathrm{Mpa}$. From the cross morphology of the fracture (Fig. 10), the long fiber extraction is mostly 
concentrated in the low-density area of the material (see the circle in Fig. 3(a)). At the position of small holes in CNTs papers, the reaction speed of the CVI gas source (including trichloromethyl-silane, hydrogen) is greater than the diffusion speed of the gas, forming a bottleneck effect ${ }^{[11]}$. The rapid densification of CNTs paper makes the matrix density between layers lower than other areas. The relative pull-out length of fibers should also be longer.

Compared with SCS composites, transfer channels in SCCS composites play an important role in significant enhancement of the bending strength. First, the transfer channels increase the density of SCCS composites as mentioned in Section 3.1. Second, the introduction of pitch-based $\mathrm{C}$ fibers can fill the mass transfer channel so that avoiding the problem of the transfer channel shrinking and leaving large holes in the subsequent CVI process ${ }^{[25]}$. In addition, when the crack propagates between the layers and encounters the transfer channel in the $\mathrm{Z}$ direction, the main crack passes through the fiber, then the $\mathrm{C}$ fiber bundle are sheared, and the remaining cracks by-pass the transfer channel and continue to expand (Fig. 10(a)). The above two expansion methods will consume a lot of energy. Thus, the mechanical properties of SCS composites are lower than SCCS composites.

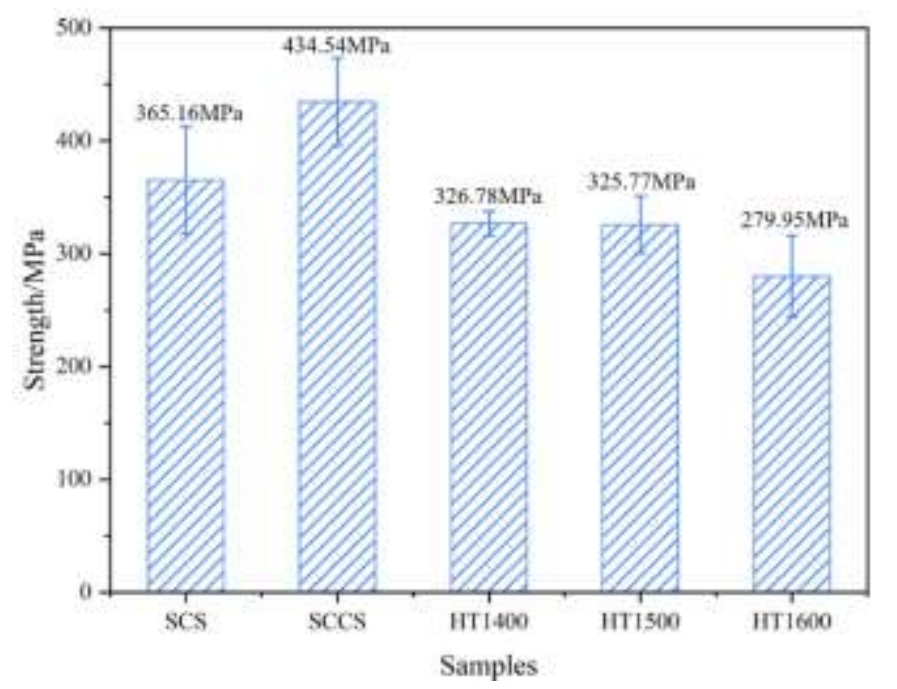

Fig. 8 The bending strength of SCCS composites after heat treatment.

When the heat treatment temperature rises, the bending strength of SCCS composites gradually decreases. On the one hand, the interlayer bonding strength of the samples decreases with the temperature increases. Owing to large difference of modulus between CNTs paper and SiC matrix, the deformation were different, which led to generation of micro-cracks. The cracks between CNTs paper layer and the SiC substrate could be clearly seen in Fig. 10(b), (d). Due to the decrease of interlayer bonding 
strength after heat treatment, the crack tends to expand along the interface between CNTs paper and SiC matrix. In this work, the interlaminar shear strength has been shown in Fig. 9. After heat treatment, the interlaminar shear strength of composites drops to about half of that at room temperature. The pitch-based-C fibers in transfer channel is completely preserved when material destroyed, indicating that the fracture surface is not in the plane where the transfer channel located. The gap between the CNTs paper layers and the SiC matrix can be observed in the fracture images of the HT1400 and HT1600 samples. On the other hand, long-term high temperature treatment improves the crystallization degree of SiC fibers, potentially leading to fibers embrittlement ${ }^{[35]}$. Although heat treatment can release the stress concentration at the crack tip and eliminate the residual stress, it cannot compensate for the damage to the mechanical properties of SiC fibers. The brittle fibers can't afford higher forces, which affects the mechanical properties of SCCS composites.

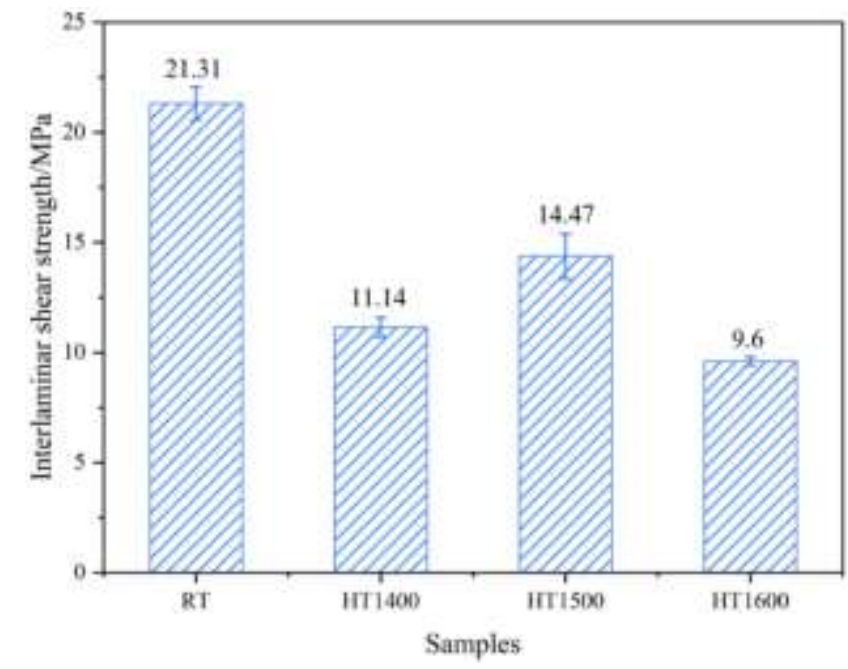

Fig. 9 The interlaminar shear strength of the composites after heat treatment.

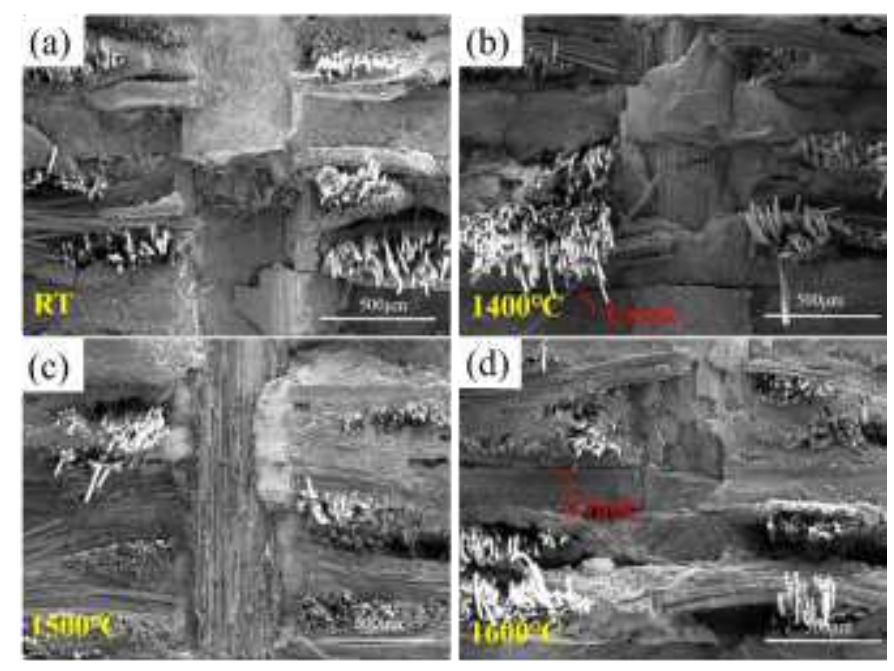

Fig. 10 Cross section of fracture at (a) room temperature; (b) $1400^{\circ} \mathrm{C}$; (c) $1500^{\circ} \mathrm{C}$; (d) $1600^{\circ} \mathrm{C}$. 
As exhibited on the fracture surface of interlaminar shear test (Fig. 11), SCCS composites exhibit three forms of failure. Cracks were generated in the plane between two notches at room temperature (Fig. 11(a)), passing through adjacent CNTs paper layer to $\mathrm{SiC}$ cloth layer until fiber cloth layer was destroyed. Multi-layer failure was observed in HT1400 composites, indicating that the main failure mode was stratified cross-over failure. The fracture of HT1500 sample was an ideal type of interlaminar failure, because the entire failure occurred at same layer, resulting in relatively pure interlaminar shear stress. Thus, the interlaminar fracture morphology was smooth. Furthermore, the modulus and hardness of CNTs paper are improved, which is conducive to the combination of CNTs paper layers and SiC matrix, resulting in abnormally increased interlayer shear strength of SCCS composites. The higher temperature reduced the hardness of the CNTs paper layer. Then cracks were easier to propagate in this layer. A large number of CNTs and scattered matrix were observed in the partial position of fracture (Fig.11(d)), which was left after the CNTs paper layer was destroyed.
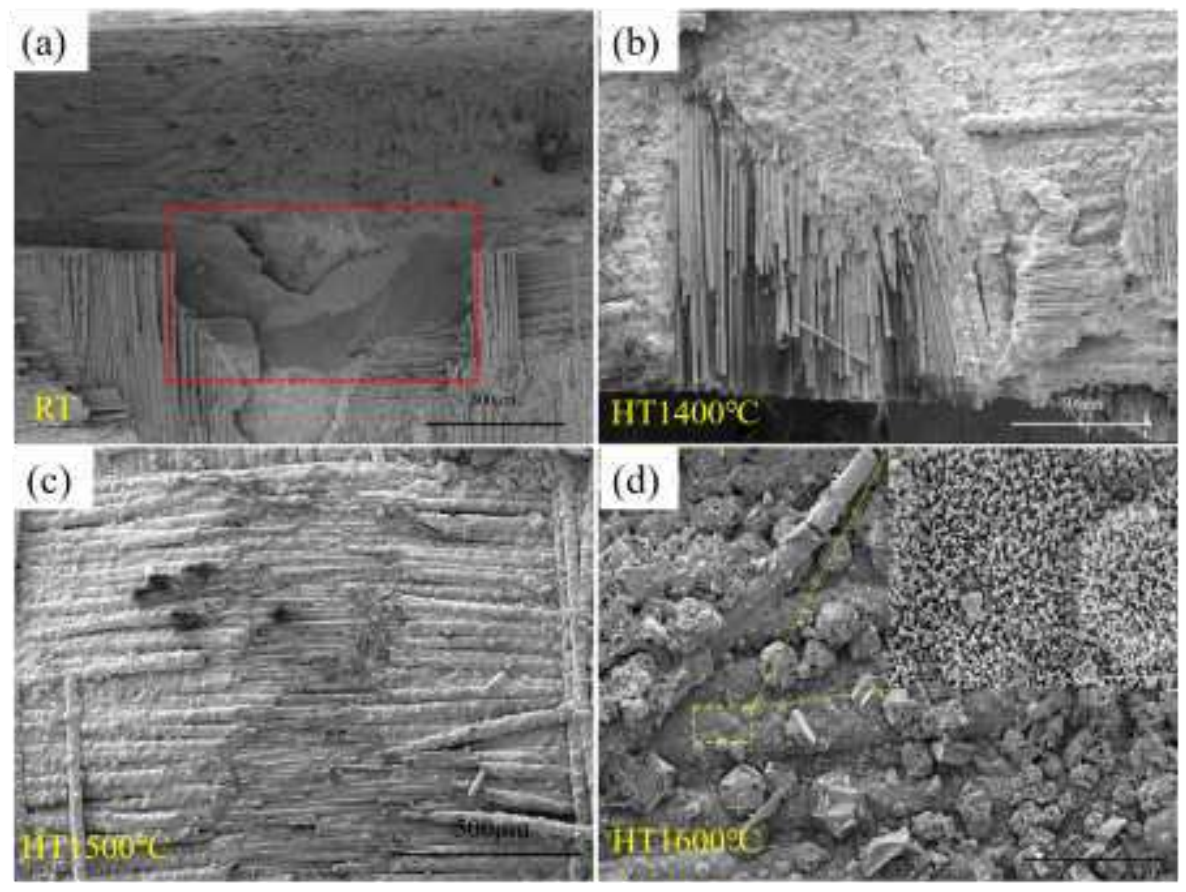

Fig. 11 Interlayer shear fracture morphology of composites at (a) room temperature; (b) $1400^{\circ} \mathrm{C}$; (c) $1500^{\circ} \mathrm{C}$; (d) $1600^{\circ} \mathrm{C}$.

\subsection{Thermal conductivity}

In Katoh's research ${ }^{[8]}$, it was pointed out that the axial thermal conductivity of composites is determined by the volume fraction of axial fiber bundle and the matrix around the fiber. Cao et al ${ }^{[36]}$ built a vertical heat transfer channels in $\mathrm{C} / \mathrm{SiC}$ composites, 
which has a positive effect on improving the thermal conductivity of the material. In this paper, the three-dimensional network formed by $\mathrm{C}$ materials (CNTs, C fibers) significantly improves the thermal conductivity of SCCS composites.

The vertical thermal conductivity of SCCS composites has been analyzed based on the parallel serial model ${ }^{[14]}$, as shown in Fig. 12. In the direction of heat transfer, the volume fraction of the PyC interface is less than $3 \%$, and its influence on thermal conductivity can be ignored ${ }^{[37]}$. Similarly, the contribution of the $\mathrm{SiC}$ matrix in the pitch-based-C/SiC micropillars to the thermal conductivity can be ignored. As a result, the SCS composites has been considered as a multilayered composite consisting of the $\mathrm{SiC} / \mathrm{SiC}$ composite layers and the CNTs paper layers. The thermal conductivity of SCCS composites could be represented as follows:

$$
\frac{1}{K_{S C C S}}=\frac{V_{S i C / S i C}}{K_{S i C / S i C}}+\frac{V_{C N T S / S \mathrm{iC}}}{K_{C N T S / S i C}}+\frac{V_{C_{f i b e r}}}{K_{C_{f i b e r}}}
$$

Where $K_{S i C / S i C}$ is the thermal conductivity of traditional $\mathrm{SiC} / \mathrm{SiC}$ composite, $K_{C N T s}$ is the thermal conductivity of carbon nanotubes, $K_{C f i b e r}$ is the thermal conductivity of pitch-based $\mathrm{C}$ fiber. $V$ is the volume fraction of each part.

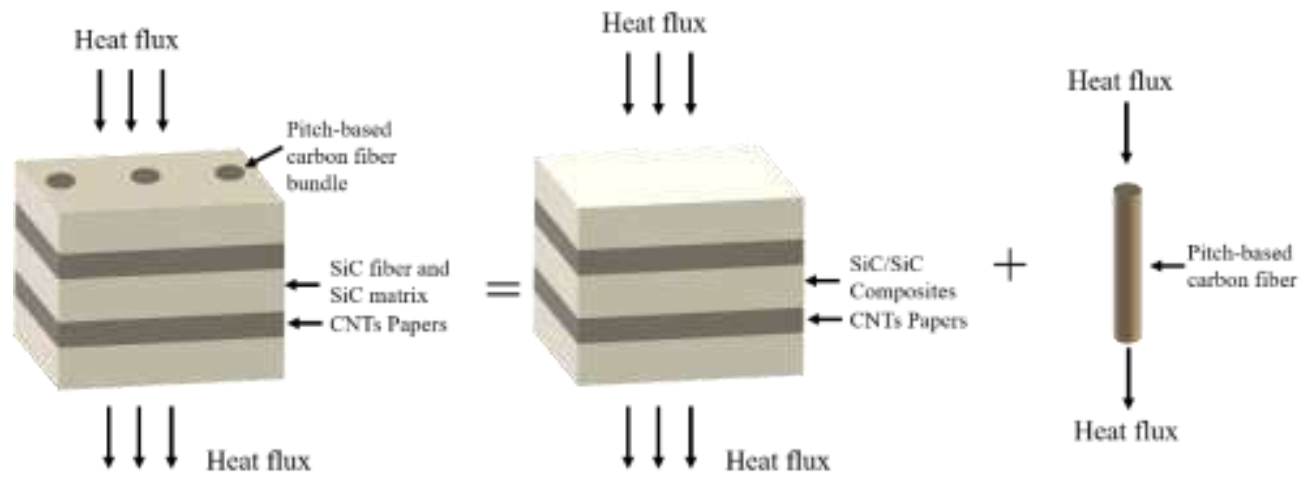

Fig. 12 Thermal conductivity calculation model of SCCS composites.

Fig. 13 exhibits vertical thermal conductivity of SCCS composites and SCS composites at room temperature. The thermal conductivity of SCS and SCCS composites is higher than that of traditional $\mathrm{SiC} / \mathrm{SiC}$ composites. The main reason is that high thermal conductivity phase provides a thermal conduction path for the transmission of phonons in SCS and SCCS composites. The vibration of phonons makes a major contribution to the heat conduction in insulating solid, which limited by phonon-boundary scattering, phonon-defect scattering and umklapp processes ${ }^{[38]}$. Considering the thermal resistance of the interface between CNTs layer and SiC matrix, the thermal conductivity of SCS composites is lower than the value calculated by Eq. 
$(2)^{[39]}$. As for SCCS composite, the vertical transfer channel prevents phonons from being transmitted to the interface and scattered.

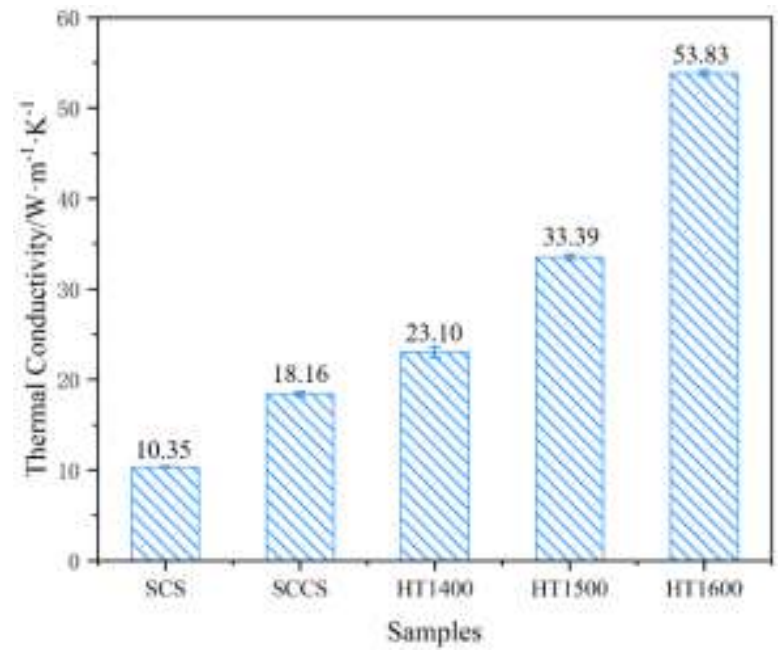

Fig. 13. Thermal conductivity of SCS and SCCS composites at room temperature (vertical direction).

In addition to high thermal conductivity phase content and transfer channels, the crystallization degree of the $\mathrm{SiC}$ matrix and $\mathrm{SiC}$ fiber can also improve the thermal conductivity of SCCS composite. The atoms in the untreated SiC fiber were arranged completely randomly. However, the disorder of the $\mathrm{SiC}$ fiber is reduced after heat treatment. Thermal conductivity can be described as follow formula in dynamics theory:

$$
K=\frac{1}{3} C v \Lambda
$$

Where $v$ is the average speed of phonons, $C$ is the specific heat capacity, and $\Lambda$ is the mean free path of phonons. According to Feng's research ${ }^{[27]}$, the higher the heat treatment temperature, the larger the grain size of the $\mathrm{SiC}$ matrix, which means that the mean free path of phonons increases. So as we see in Fig. 13, the thermal conductivity of SCCS composites increase to 2.96 times with the temperature of treatment rises from room temperature to $1600^{\circ} \mathrm{C}$.

In-plane thermal diffusivity and thermal conductivity of SCCS composites were exhibited in Table 3.

Table 3 In-plane thermal diffusivity and thermal conductivity of SCCS composites at room temperature and after $1600^{\circ} \mathrm{C}$ heat treatment.

\begin{tabular}{cccc}
\hline SCCS composites & Test temperature $/{ }^{\circ} \mathrm{C}$ & $\begin{array}{c}\text { Thermal } \\
\text { diffusivity } / \mathrm{mm} / \mathrm{s}^{2}\end{array}$ & $\begin{array}{c}\text { Thermal } \\
\text { conductivity } / \mathrm{W} /(\mathrm{m} \bullet \mathrm{K})\end{array}$ \\
\hline RT & 25.1 & 7.47 & 18.60 \\
HT1600 & 25.1 & 11.99 & 29.85 \\
\hline
\end{tabular}


Generally, the interfacial thermal resistance was considered when it was not parallel to the direction of heat flow. In CNTs layers, abundant interfaces between CNTs and $\mathrm{SiC}$ matrix were randomly distributed and hinder the heat transfer. The thermal conductivity of $\mathrm{CNTs} / \mathrm{SiC}$ ceramic is much lower than theoretical thermal conductivity of $\mathrm{CNT}^{[40]}$. The direction of transfer channels were perpendicular to the direction of plane heat flow, which could not improve the efficiency of phonon transfer. On the contrary, the interface thermal resistance between transfer channels and CNTs/SiC ceramic layers, $\mathrm{SiC} / \mathrm{SiC}$ composite layers were generated. As the data in Table 3 shows, in-plane thermal conductivity were similar to vertical thermal conductivity (Fig. 13) of SCCS composites at room temperature. In-plane thermal conductivity shown the same trend as vertical thermal conductivity due to higher degree of crystallization after $1600^{\circ} \mathrm{C}$ heat treatment.

\section{Conclusion}

In this paper, the heat treatment of $\mathrm{SiC}-\mathrm{CNTs}-\mathrm{C} / \mathrm{SiC}$ composites prepared by $\mathrm{CVI}$ has been studied. The microstructure, the bonding status between CNTs/SiC layer and $\mathrm{SiC}$ matrix, the mechanical properties and the thermal conductivity were discussed.

After heat treatment, grain size of $\mathrm{SiC}$ fibers raised and the crystallization degree of the $\mathrm{SiC}$ matrix increased. At $1600^{\circ} \mathrm{C}, \mathrm{SiC}$ matrix showed two shapes: triangular pyramid-shaped sharp or hexagonal prism-shaped.

The elastic modulus and hardness of CNTs paper layers had decreased due to the growth of grains. Although transfer channel consumes energy and had a certain reinforcing effect, $\mathrm{SiC}$ fibers could not withstand long-term high temperature treatment. Thus, the bending strength of heat-treated SCCS composites was lower than that of composites untreated.

CNTs paper and pitch-based $\mathrm{C}$ fiber construct the three-dimensional network structure of carbon materials, which plays an important role in improving the thermal conductivity of SCCS composites. After heat treatment, the rise of mean free path of phonons increases the thermal conductivity (vertical direction) to 2.96 times. In plane, a large number of interfacial phases reduced advantage of CNT in thermal conductivity and the existence of transfer channels increased interfacial thermal resistance. As a result, in-plane thermal conductivity was close to vertical thermal conductivity.

\section{Acknowledgement}

This work is supported by the National Natural Science Foundation of China (No. 
92060202), the National Key Research and Development Program of China (No. 2018YFB1106600), Chinese National Foundation for Natural Sciences under Contracts (No. 51672217, No. 51572224, No. 51972269) and the Fundamental Research Funds for the Central Universities (No. 3102019ghxm014).

\section{References}

[1] Yoshida K. Development of silicon carbide fiber-reinforced silicon carbide matrix composites with high performance based on interfacial and microstructure control[J]. Journal of the Ceramic Society of Japan, 2010, 118(1374): 82-90.

[2] Kerans R. J., Hay R. S., Parthasarathy T. A., et al. Interface design for oxidation-resistant ceramic composites[J]. Journal of the American Ceramic Society, 2002, 85(11): 2599-632.

[3] Luan X. G., Xu X. M., Zou Y., et al. Wet oxidation behavior of SiC/(SiC- SiBCN)x composites prepared by CVI combined with PIOP process[J]. Journal of the American Ceramic Society, 2019, 102(10): 6239-55.

[4] Jones Russell H, Giancarli L, Hasegawa Akira, et al. Promise and Challenges of SiCf/SiC Composites for Fusion Energy Applications[J]. 2002, 307(3): 1057-72.

[5] Li M., Zhou X. B., Yang H., et al. The critical issues of SiC materials for future nuclear systems[J]. Scripta Materialia, 2018, 143: 149-53.

[6] Muroga T., Gasparotto M., Zinkle S. J. Overview of materials research for fusion reactors[J]. Fusion Engineering and Design, 2002, 61-62: 13-25.

[7] Ivekovic A., Novak S., Drazic G., et al. Current status and prospects of SiCf/SiC for fusion structural applications[J]. Journal of the European Ceramic Society, 2013, 33(10): 1577-89.

[8] Katoh Y., Nozawa T., Snead L. L., et al. Property tailorability for advanced CVI silicon carbide composites for fusion[J]. Fusion Engineering and Design, 2006, 81(8-14): 937-44.

[9] Yamada R., Igawa N., Taguchi T. Thermal diffusivity/conductivity of Tyranno SA fiber- and HiNicalon Type S fiber-reinforced 3-D SiC/SiC composites[J]. Journal of Nuclear Materials, 2004, 329: 497-501.

[10] Weizhong Zhang, Xiaoming Ma, Chen Xiujuan. Development and Application of Preparation Technology of Continuous SiC Fiber[J]. Aeronautical Manufacturing Technology, 2012, 18: 105-07.

[11] Tao P. F., Wang Y. G. Improved thermal conductivity of silicon carbide fibers-reinforced silicon carbide matrix composites by chemical vapor infiltration method[J]. Ceramics International, 2019, 45(2): 2207-12.

[12] Pop E., Mann D., Wang Q., et al. Thermal conductance of an individual single-wall carbon nanotube above room temperature[J]. Nano Letters, 2006, 6(1): 96-100.

[13] Feng Wei., Zhang L. T., Liu Y. S., et al. Fabrication of SiCf-CNTs/SiC composites with high thermal conductivity by vacuum filtration combined with CVI[J]. Materials Science and Engineering a-Structural Materials Properties Microstructure and Processing, 2016, 662: 506-10.

[14] Feng Wei, Zhang Litong, Liu Yongsheng, et al. The improvement in the mechanical and thermal properties of $\mathrm{SiC} / \mathrm{SiC}$ composites by introducing CNTs into the PyC interface[J]. Materials Science and Engineering: A, 2015, 637: 123-29.

[15] Yoshida Katsumi, Kajikawa Satoshi, Yano Toyohiko. Microstructure design and control for improvement of thermal conductivity of $\mathrm{SiCf} / \mathrm{SiC}$ composites[J]. Journal of Nuclear Materials, 2013, 
440(1-3): 539-45.

[16] Naslain R., Langlais F., Vignoles G., et al. The CVI-process : state of the art and perspective[J]. Ceramic Engineering and Science Proceedings, 2007, 27(2): 373-86.

[17] Katoh Y., Kotani M., Kishimoto H., et al. Properties and radiation effects in high-temperature pyrolyzed PIP-SiC/SiC[J]. Journal of Nuclear Materials, 2001, 295(1): 131.

[18] Katoh Y., Dong S. M., Kohyama A. Thermo-mechanical properties carbide composites fabricated and microstructure of silicon by nano-infiltrated transient eutectoid process[J]. Fusion Engineering and Design, 2002, 61-62: 723-31.

[19] Kowbel W., Bruce C. A., Tsou K. L., et al. High thermal conductivity SiC/SiC composites for fusion applications[J]. Journal of Nuclear Materials, 2000, 283: 570-73.

[20] Novak S., Rade K., Konig K., et al. Electrophoretic deposition in the production of $\mathrm{SiC} / \mathrm{SiC}$ composites for fusion reactor applications[J]. Journal of the European Ceramic Society, 2008, 28(14): 2801-07.

[21] Wang J., Chen X., Guan K., et al. Effects of channel modification on microstructure and mechanical properties of $\mathrm{C} / \mathrm{SiC}$ composites prepared by LA-CVI process[J]. Ceramics International, 2018, 44(14): 16414-20.

[22] Wang J., Wang C. H., Liu Y. S., et al. Microstructure and chemical bond evolution of diamond-like carbon films machined by femtosecond laser[J]. Applied Surface Science, 2015, 340: 49-55.

[23] Wang J., Liu Y., Cheng L., et al. Enhanced Mechanical and Electromagnetic-Wave-Absorption Properties of Ceramic Matrix Composites Fabricated by Novel Laser-Machining-Assisted CVI[J]. Journal of Ceramic Science and Technology, 2018, 9(1): 79-84.

[24] Wang J., Cheng L. F., Liu Y. S., et al. Enhanced densification and mechanical properties of carbon fiber reinforced silicon carbide matrix composites via laser machining aided chemical vapor infiltration[J]. Ceramics International, 2017, 43(14): 11538-41.

[25] Wang J., Liu Y., Wang C., et al. Character and mechanism of surface micromachining for C/SiC composites by ultrashort plus laser[J]. Advances in Applied Ceramics, 2017, 116(2): 99-107.

[26] Ma X. K., Yin X. W., Cao X. Y., et al. Effect of heat treatment on the mechanical properties of $\mathrm{SiCf} / \mathrm{BN} / \mathrm{SiC}$ fabricated by CVI[J]. Ceramics International, 2016, 42(2): 3652-58.

[27] Feng W., Zhang L. T., Liu Y. S., et al. Increasing the thermal conductivity of 2D SiC/SiC composites by heat-treatment[J]. Fusion Engineering and Design, 2015, 90: 110-18.

[28] Cao S. Y., Wang J., Wang H. Effect of heat treatment on the microstructure and tensile strength of KD-II SiC fibers[J]. Materials Science and Engineering A, 2016, 673: 55-62.

[29] Moreno P., Mendez C., Garcia A., et al. Femtosecond laser ablation of carbon reinforced polymers[J]. Applied Surface Science, 2006, 252(12): 4110-19.

[30] Wu Z. C., Chen Z. H., Du X., et al. Transparent, conductive carbon nanotube films[J]. Science, 2004, 305(5688): 1273-76.

[31] Araki Hiroshi, Suzuki Hiroshi, Wen Yang, et al. Effect of high temperature heat treatment in vacuum on microstructure and bending properties of $\mathrm{SiCf} / \mathrm{SiC}$ composites prepared by CVI[J]. Journal of Nuclear Materials, 1998, 258-263(4): 1540-45.

[32] Chin J., Gantzel P. K., Hudson R. G. Structure of chemical vapor-deposited silicon-carbide[J]. Thin Solid Films, 1977, 40: 57-72.

[33] Oliver W. C., Pharr G. M. An improved technique for determining hardness and elastic-modulus using load and displacement sensing indentation experiments[J]. Journal of Materials Research, 1992, 7(6): $1564-83$. 
[34] Lide Z Jimei M. Nanomaterials and Nanostructures [M]. Bei Jing: Beijing Science and Technology Publishing Co., Ltd, 2001.

[35] Wang X., Wang K. J., Bai H., et al. Creep Properties and Damage Mechanisms of 2D-SiCf/SiC Composites Prepared by CVI [J]. Journal of Inorganic Materials, 2020, 35(7): 817-21.

[36] Cao L. Y., Liu Y. S., Zhang Y. H., et al. Enhancing thermal conductivity of C/SiC composites containing heat transfer channels [J]. Journal of the European Ceramic Society, 2020, 40(10): 3520-7.

[37] Nguyen B. N., Henager C. H. Fiber/matrix interfacial thermal conductance effect on the thermal conductivity of SiC/SiC composites [J]. Journal of Nuclear Materials, 2013, 440(1-3): 11-20.

[38] Shin Sunmi, Wang Qingyang, Luo Jian, et al. Advanced Materials for High-Temperature Thermal Transport [J]. Advanced Functional Materials, 2020, 30(8): 1904815.

[39] Huxtable S. T., Cahill D. G., Shenogin S., et al. Interfacial heat flow in carbon nanotube suspensions [J]. Nature Materials, 2003, 2(11): 731-4.

[40] Han, Daoyang, Mei, et al. A direct chemical vapor infiltration route for a carbon nanotube/silicon carbide thermal protection system [J]. Journal of Alloys Compounds, 2018, 
Figures
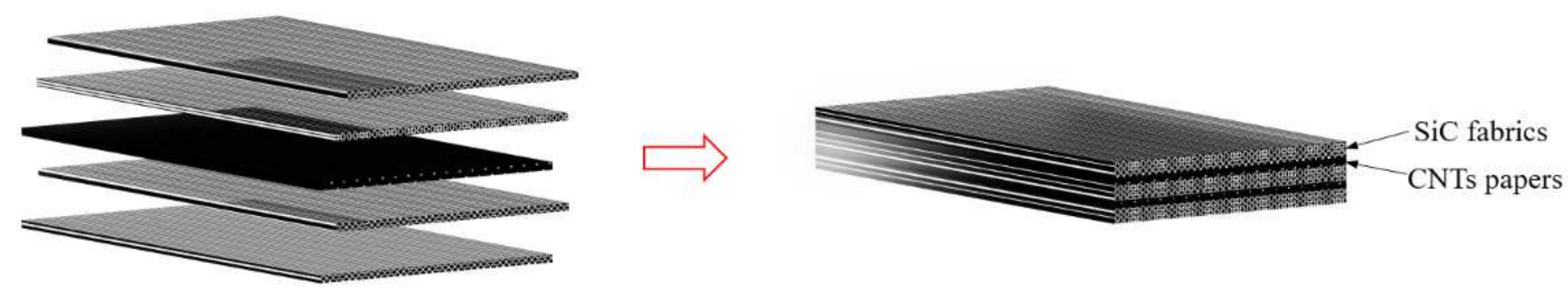

Figure 1

Stacking pattern of SiC-CNTs/SiC composites(SCS). 

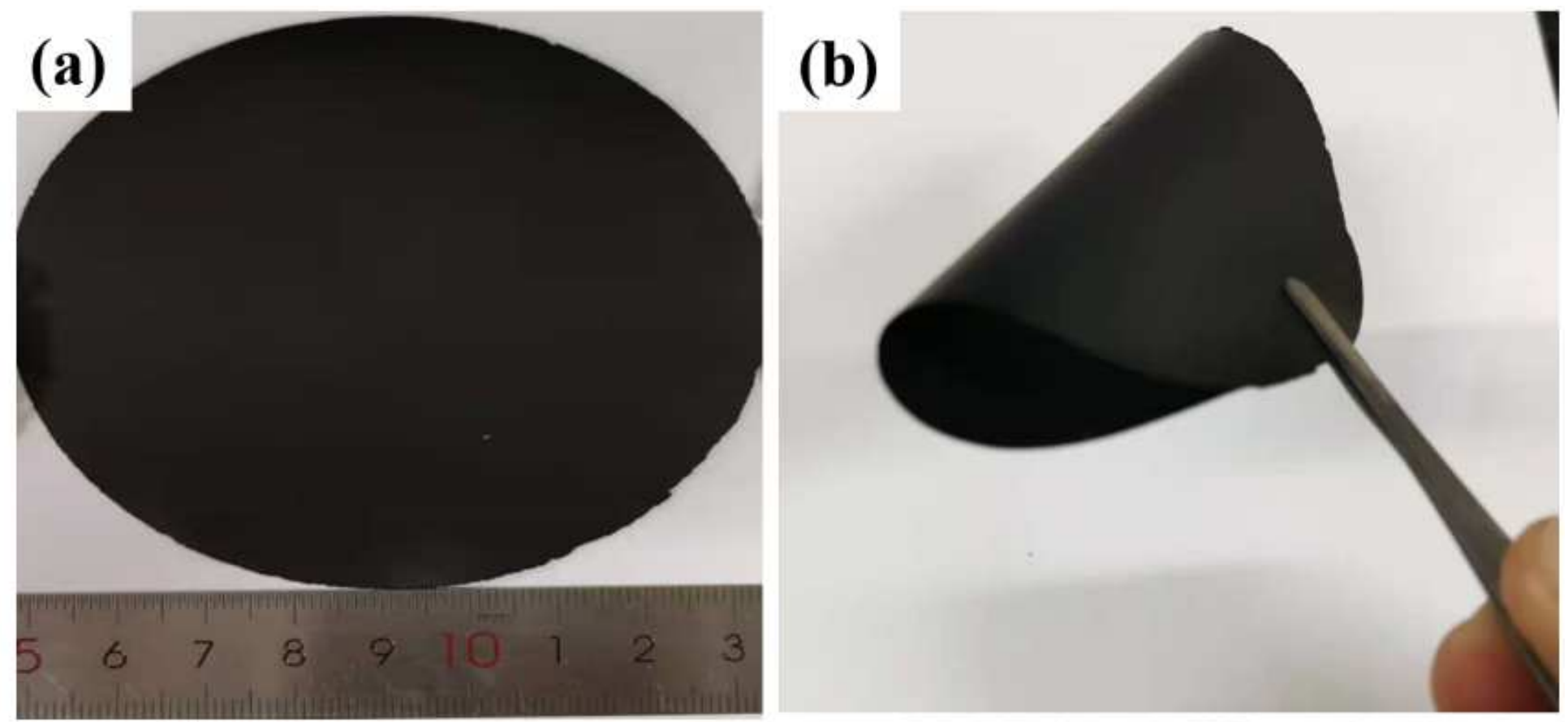

\section{(c)}

\section{(d)}
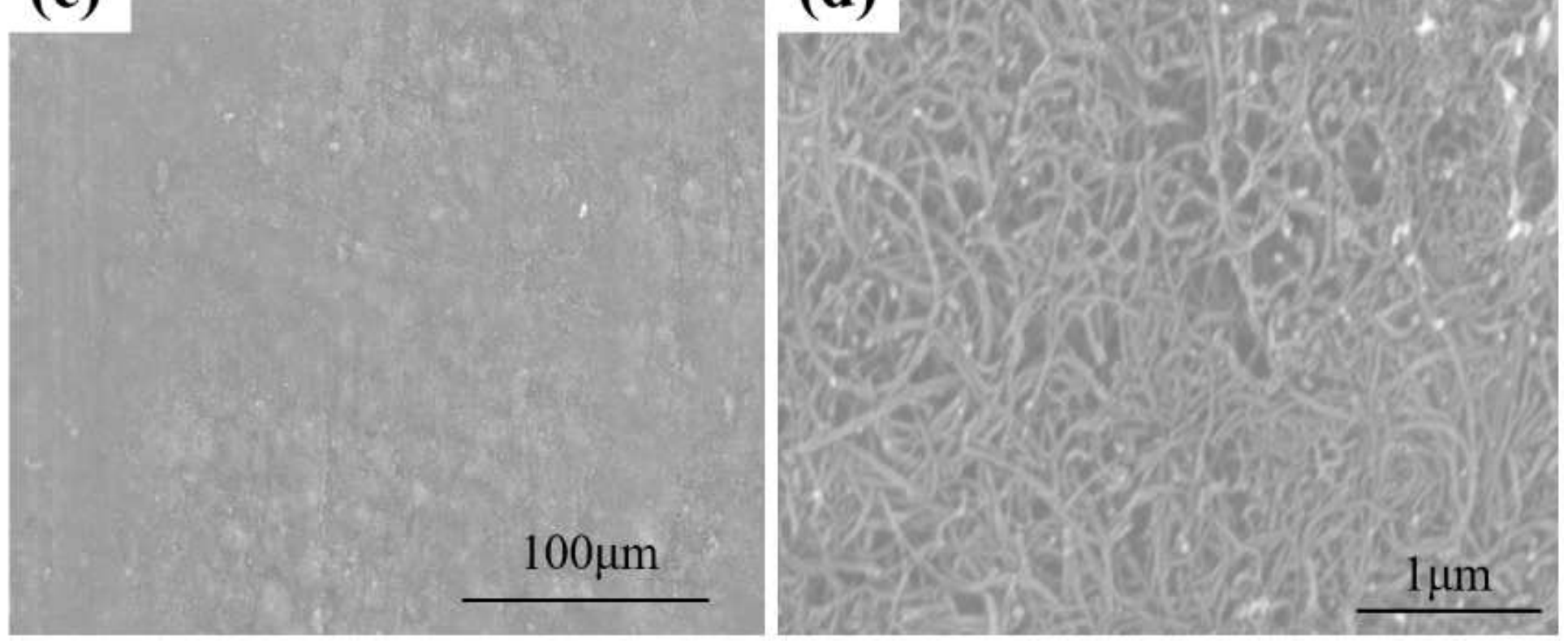

\section{Figure 2}

Morphologies of CNTs paper. (a) macro view; (b) flexibility of CNT paper (c) CNT paper at low magnification; (d) CNT paper at high magnification. 


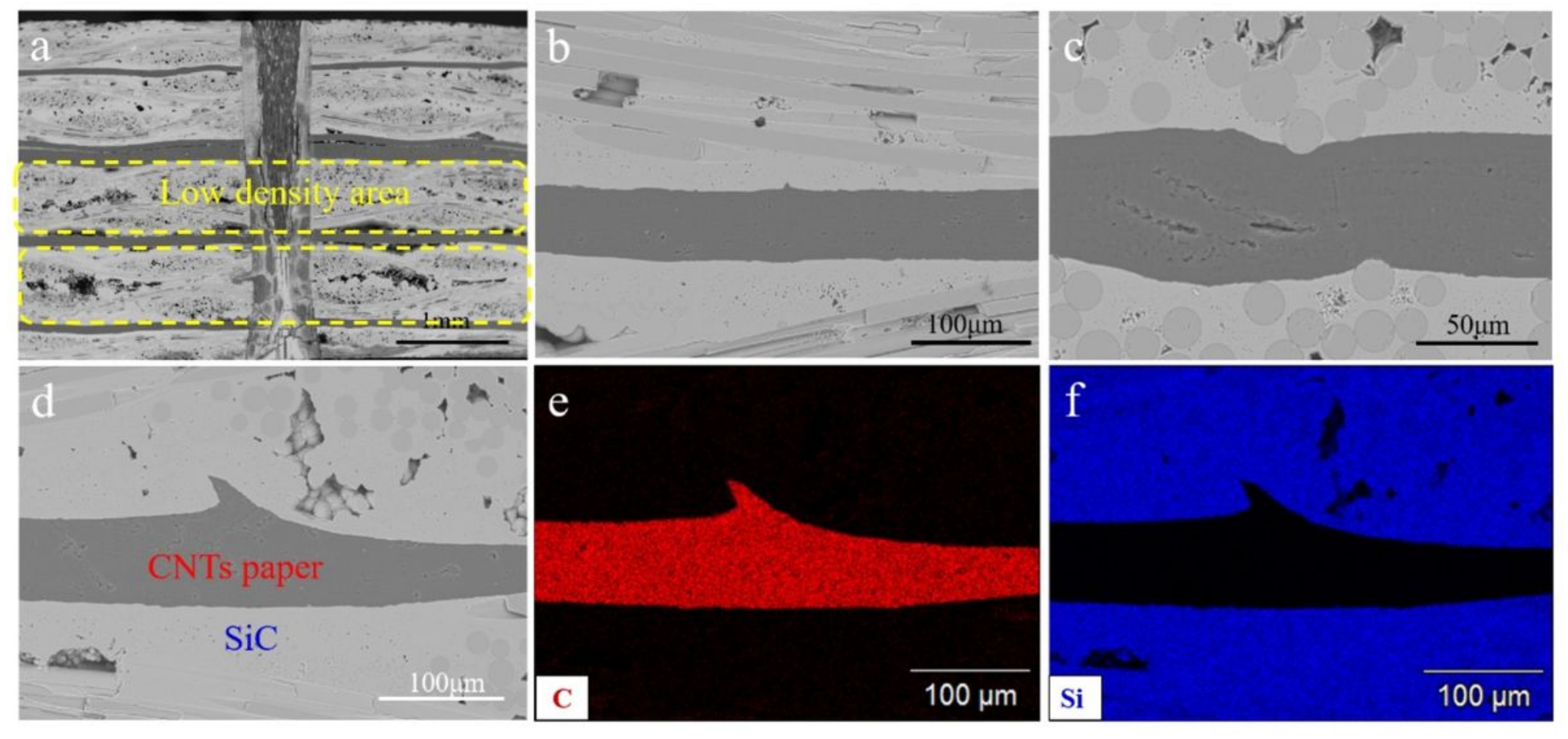

Figure 3

Morphologies of CNTs paper layers in SCS composite. (a)-(c) BSE images of SCCS composite. (d)-(f) Energy dispersive near the CNTs papers. 

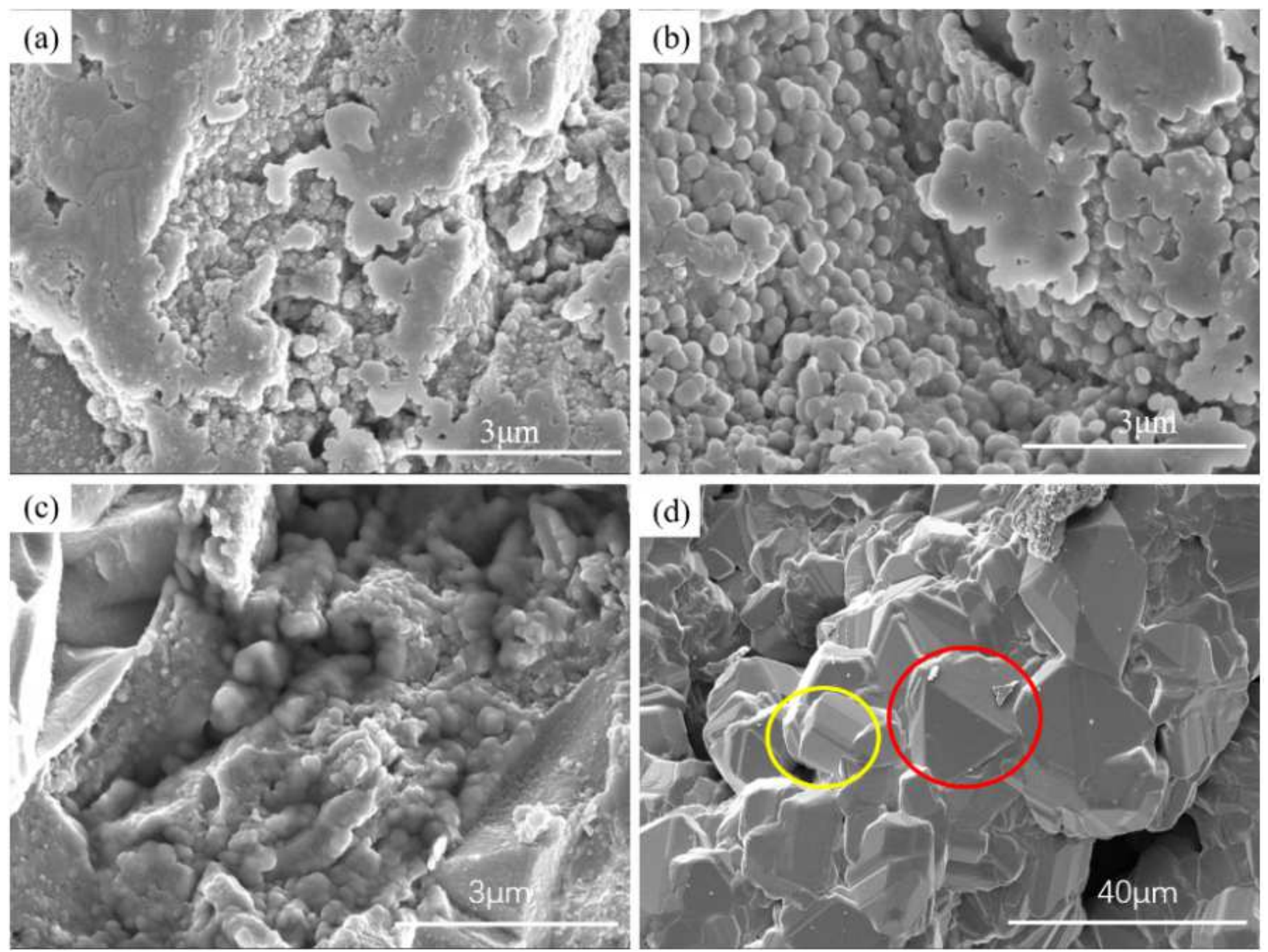

\section{Figure 4}

Morphology of SiC matrix after heat treatment at different temperatures for 2 hours. (a) Room temperature; (b) 1400冈 treatment; (c) 1500® treatment; (d) 1600冈 treatment. 


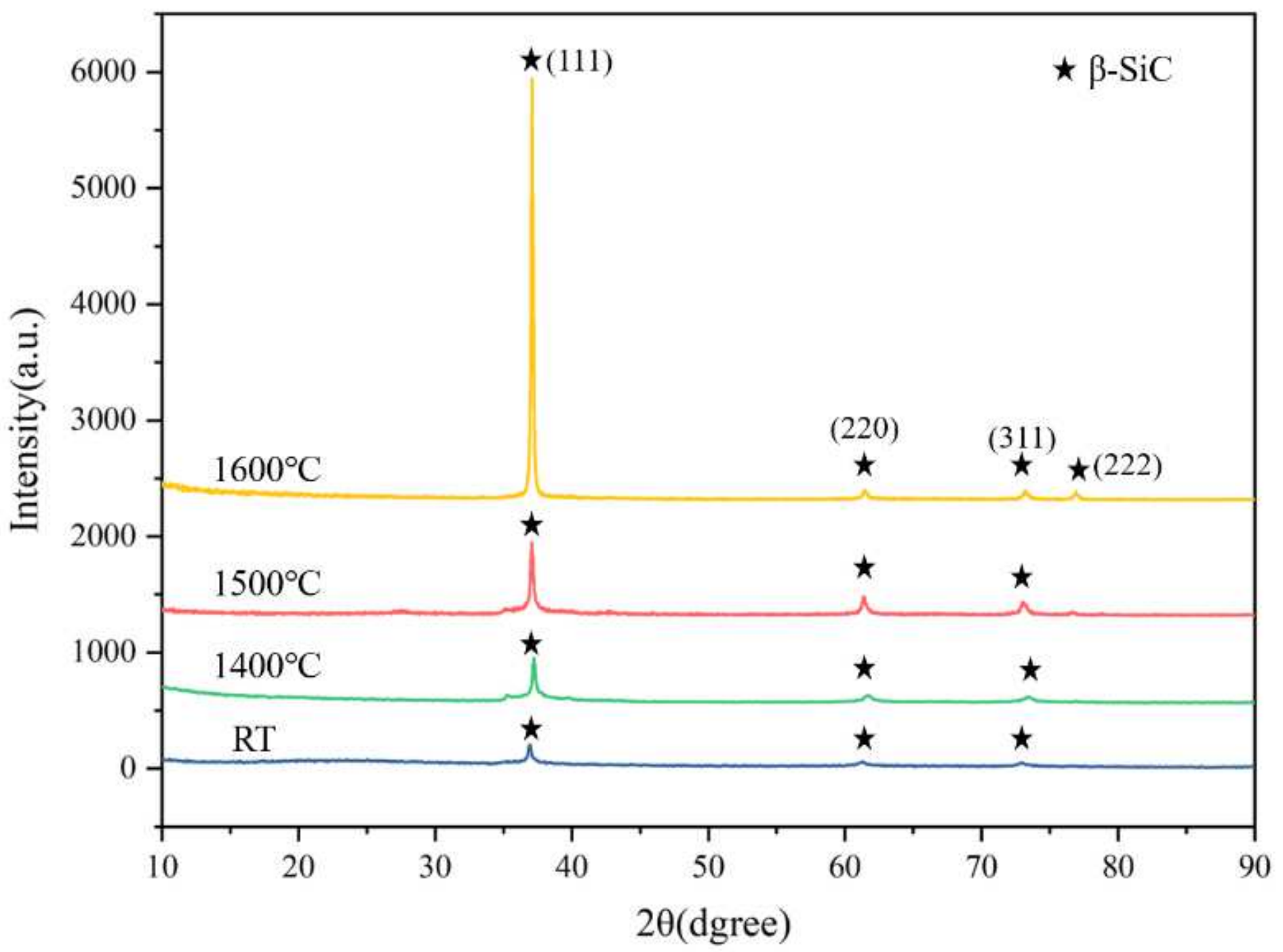

Figure 5

X-ray diffraction patterns of samples at different heat treatment temperatures.
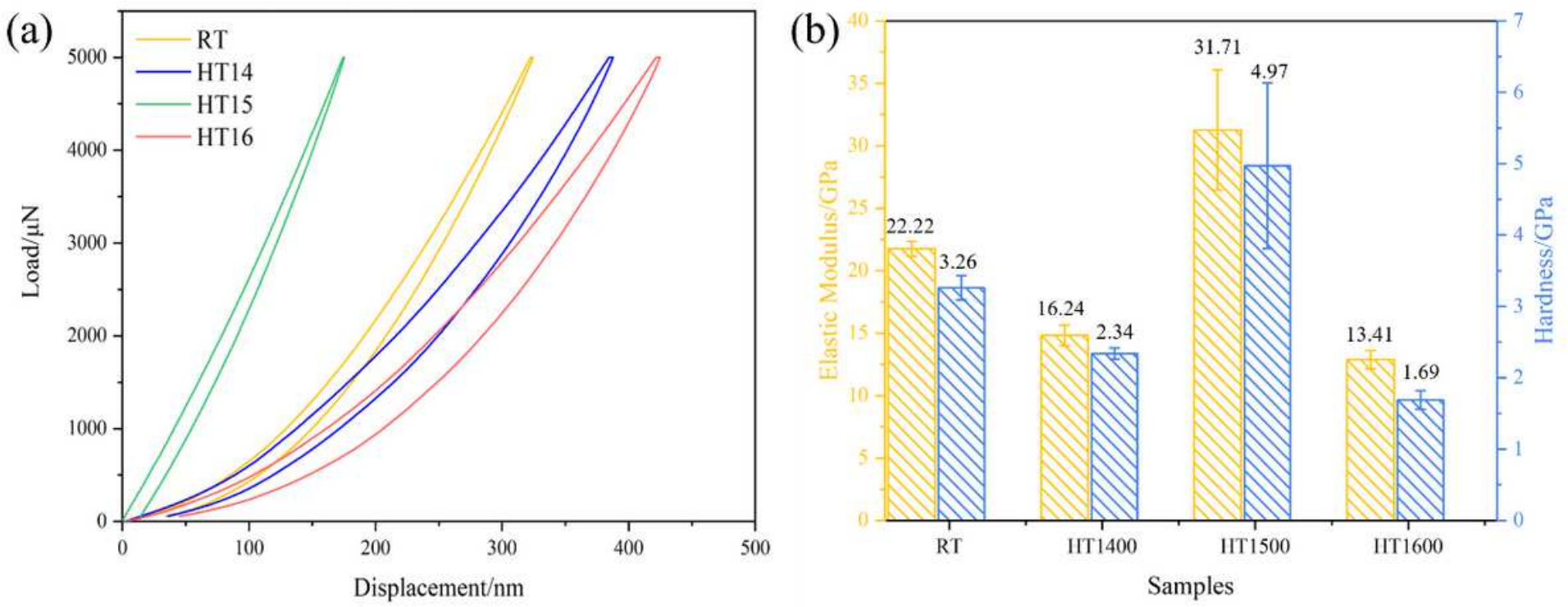
Figure 6

Micromechanical properties of CNTs paper layers in SCCS composites (tested by nanoindentation). (a) Load-Displacement curves of CNTs papers; (b) Elastic modulus and Hardness of CNTs papers after heat treatment.

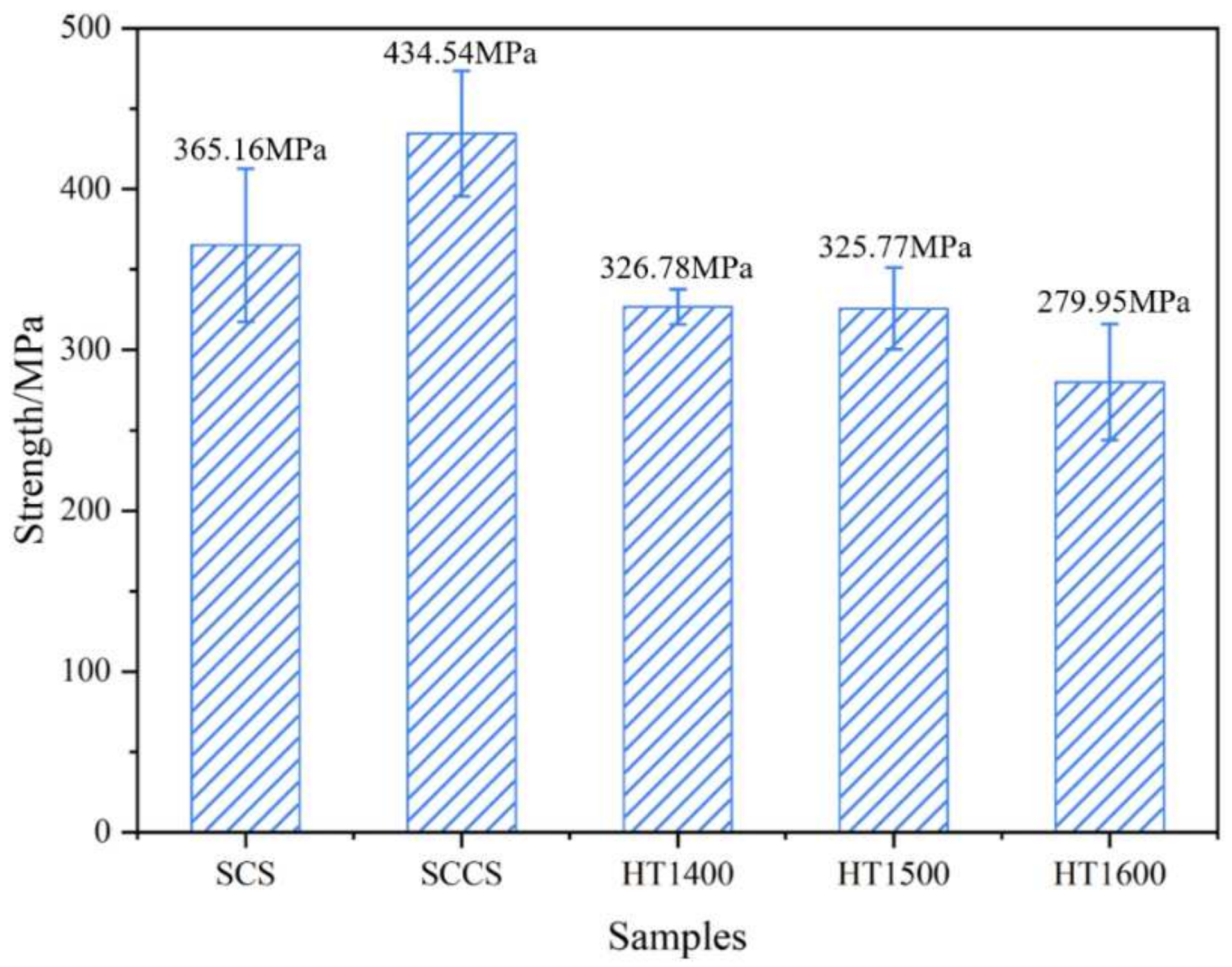

Figure 7

The bending strength of SCCS composites after heat treatment. 


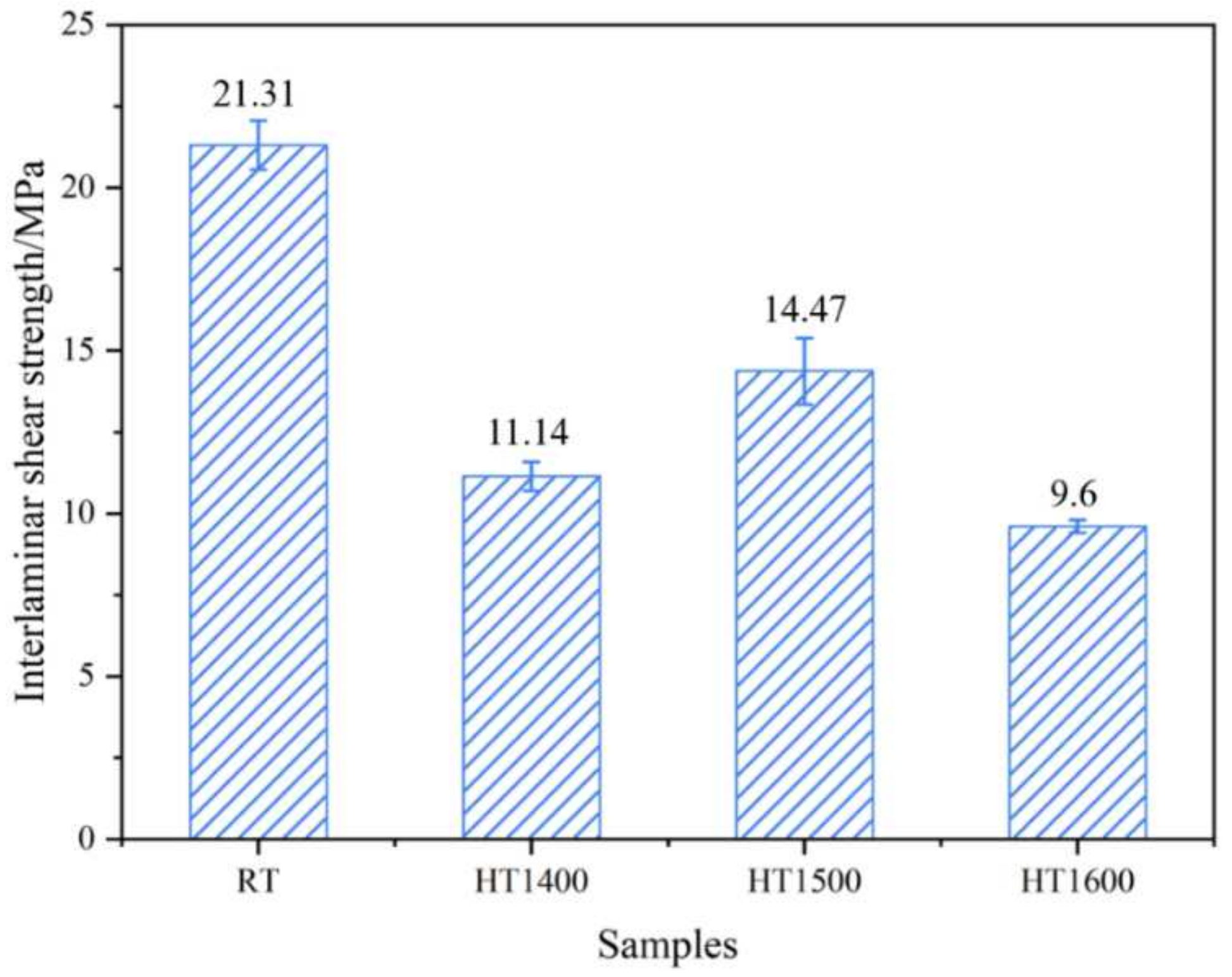

Figure 8

The interlaminar shear strength of the composites after heat treatment. 

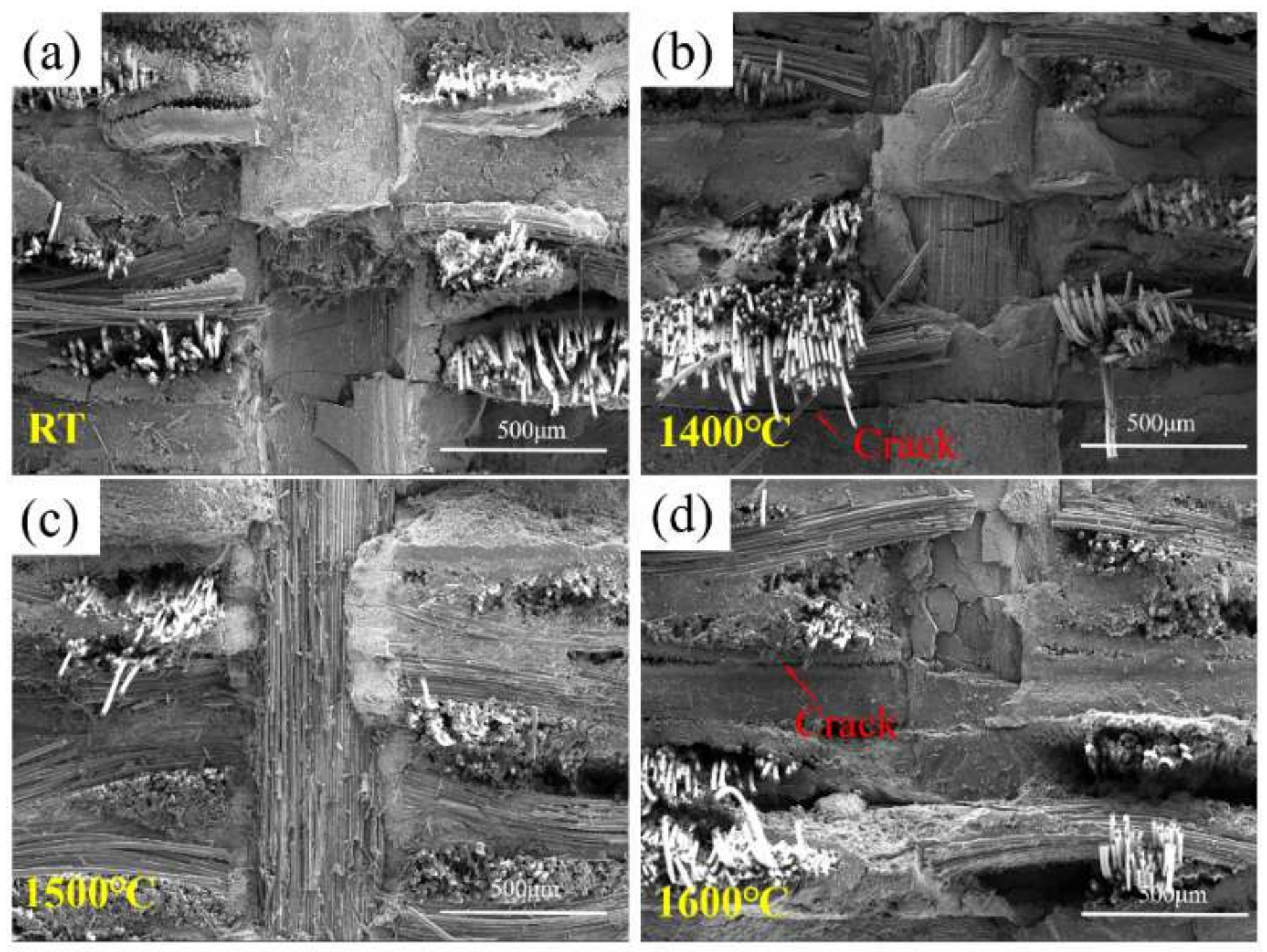

\section{Figure 9}

Cross section of fracture at (a) room temperature; (b) 1400冈; (c) 1500邓; (d) 1600》. 

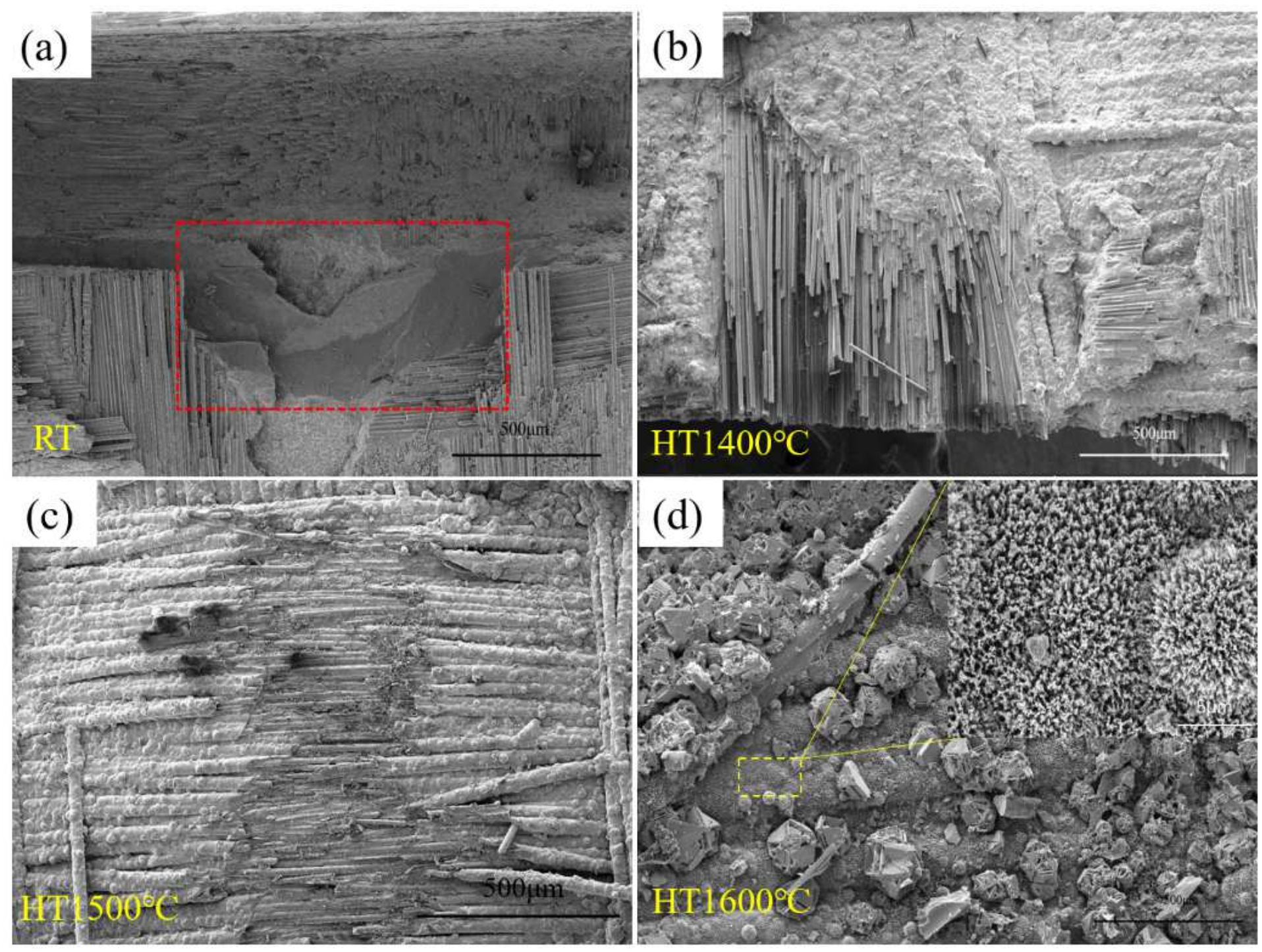

\section{Figure 10}

Interlayer shear fracture morphology of composites at (a) room temperature; (b) 1400®; (c) 1500®; (d) 1600区.
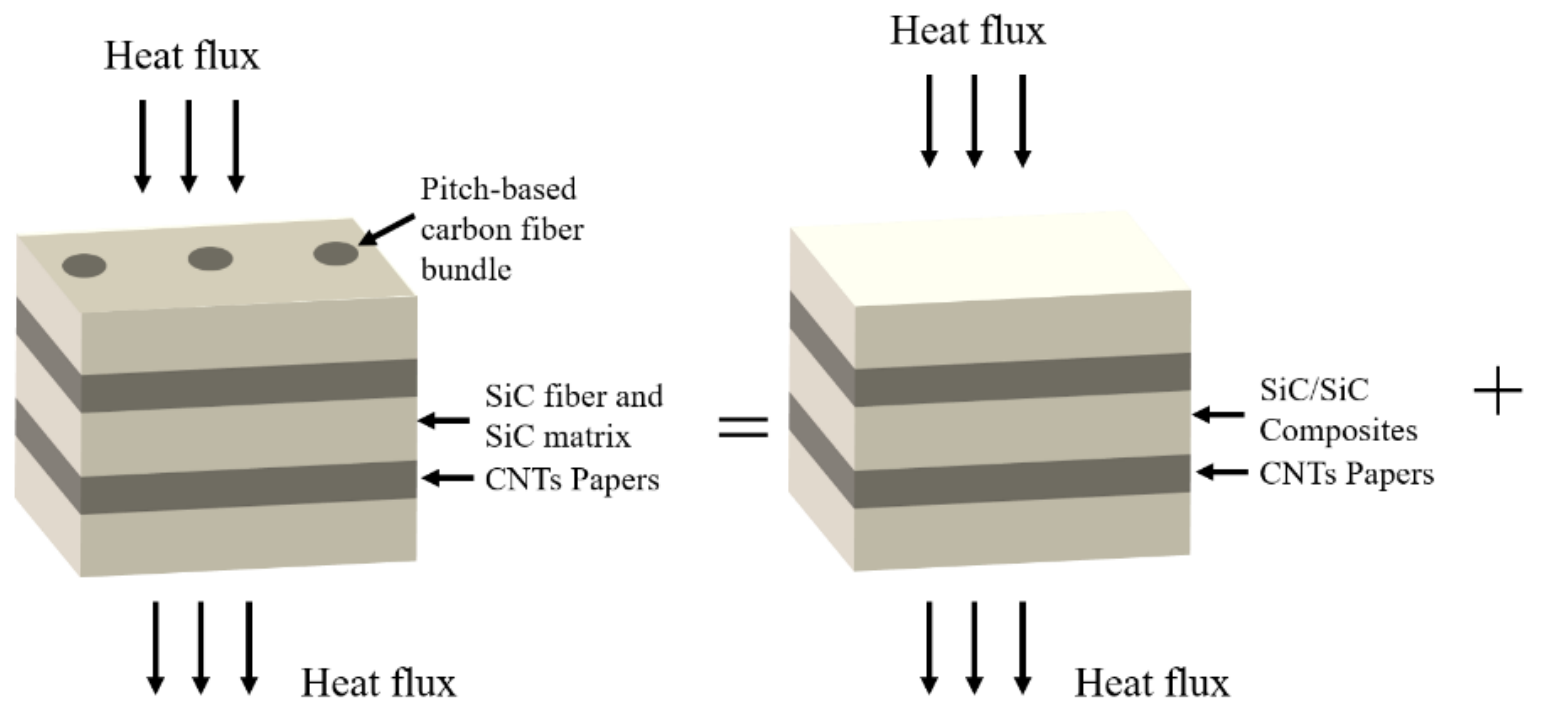

Heat flux

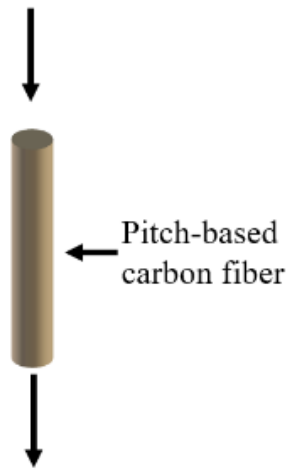

Heat flux 
Figure 11

Thermal conductivity calculation model of SCCS composites.

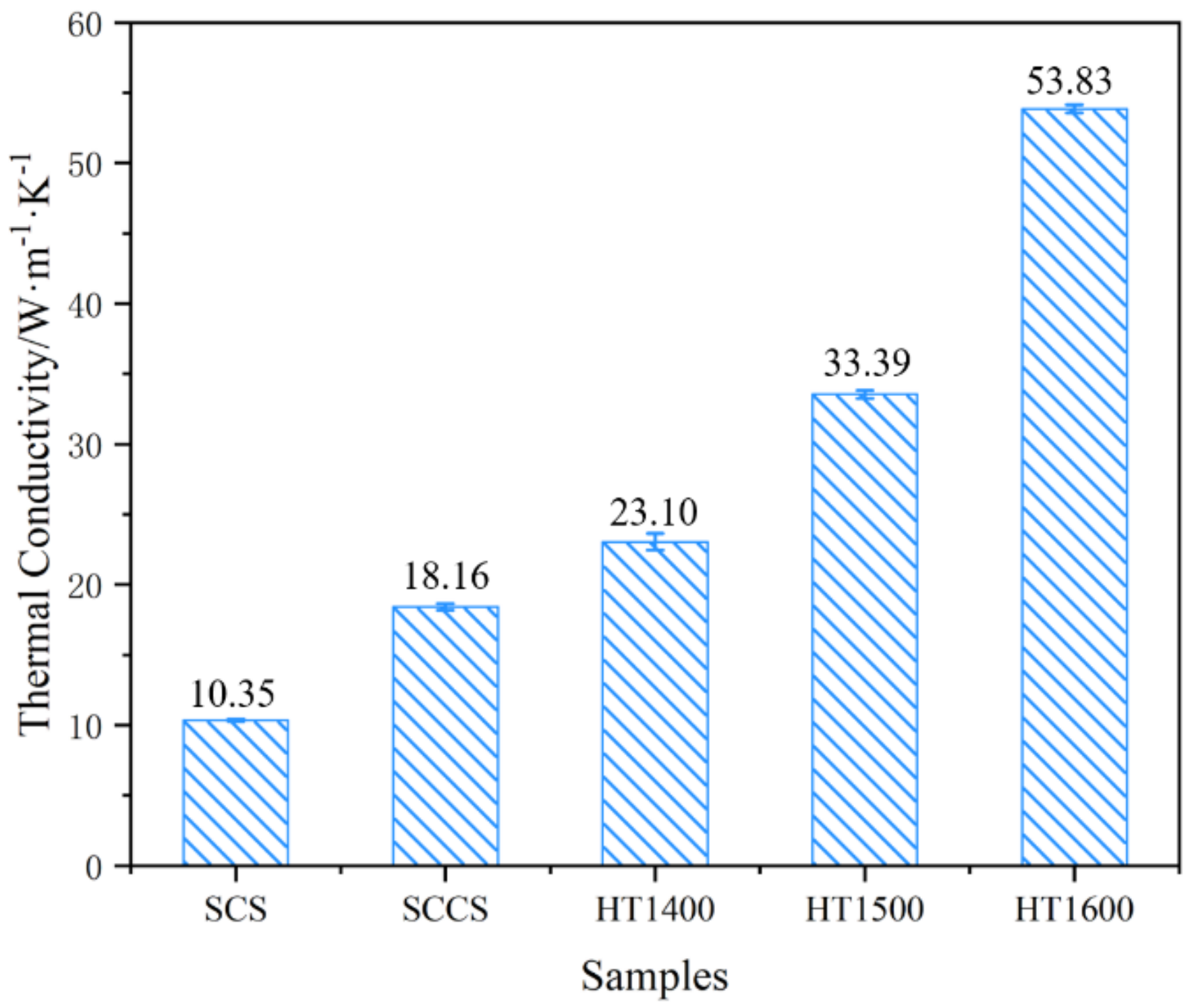

Figure 12

Thermal conductivity of SCS and SCCS composites at room temperature (vertical direction). 